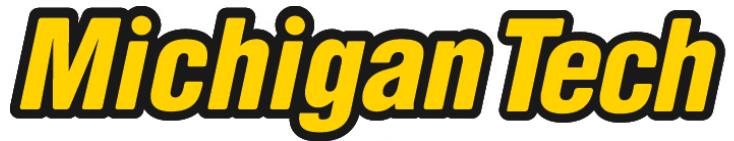 \\ Michigan Technological University Create the Future Digital Commons @ Michigan Tech
}

Dissertations, Master's Theses and Master's Reports - Open

Dissertations, Master's Theses and Master's

Reports

2012

Sleep Deprivation and Pain Intensity

Robert Arnold Larson

Michigan Technological University

Follow this and additional works at: https://digitalcommons.mtu.edu/etds

Part of the Physiology Commons

Copyright 2012 Robert Arnold Larson

\section{Recommended Citation}

Larson, Robert Arnold, "Sleep Deprivation and Pain Intensity", Master's Thesis, Michigan Technological University, 2012.

https://doi.org/10.37099/mtu.dc.etds/465

Follow this and additional works at: https://digitalcommons.mtu.edu/etds

Part of the Physiology Commons 


\title{
SLEEP DEPRIVATION AND PAIN INTENSITY
}

\author{
By \\ Robert Arnold Larson
}

\begin{abstract}
A THESIS
Submitted in partial fulfillment of the requirements for the degree of

MASTER OF SCIENCE

In Biological Sciences
\end{abstract}

MICHIGAN TECHNOLOGICAL UNIVERSITY

2012

(C) 2012 Robert Arnold Larson 
This thesis has been approved in partial fulfillment of the requirements for the Degree of MASTER OF SCIENCE in Biological Sciences

Department of Biological Sciences

Thesis Advisor: $\quad$ Dr. Jason R. Carter

Committee Member: Dr. Qing-Hui Chen

Committee Member: $\quad$ Dr. John J. Durocher

Committee Member: $\quad$ Dr. Thomas D. Drummer

Department Chair: Dr. Chandrashekhar P. Joshi 


\section{Table of Contents}

Table of Contents............................................................................................................................................. ii

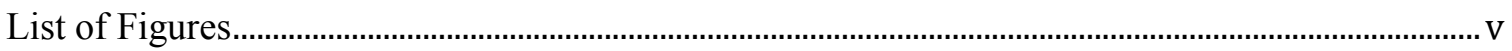

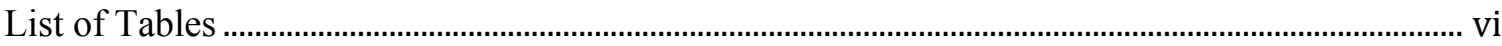

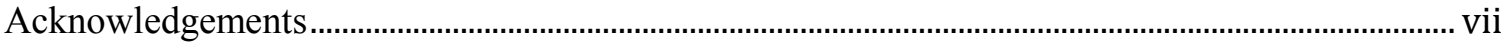

List of Abbreviations................................................................................................................................. viii

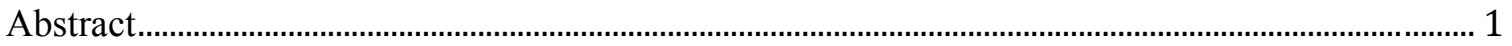

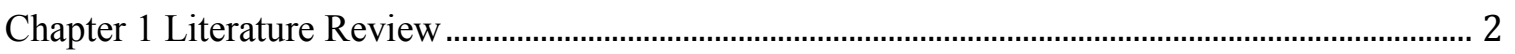

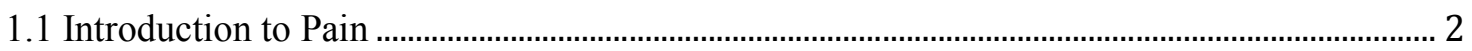

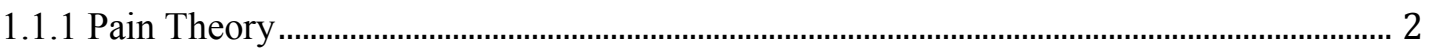

1.1.2 Anatomy of Pain.................................................................................................................... 5

1.1.3 Sex Differences in the Perception of Pain.............................................................................. 9

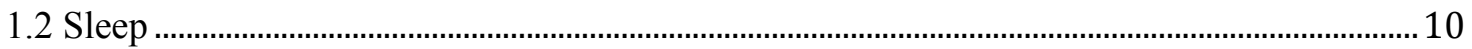

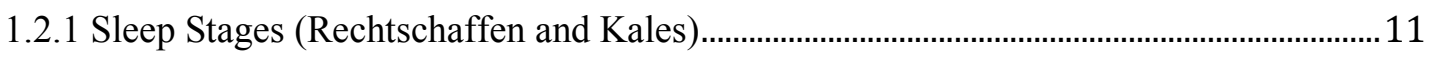

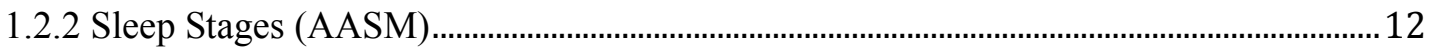

1.2.3 The Two-Process Model of Sleep Regulation ..........................................................................13

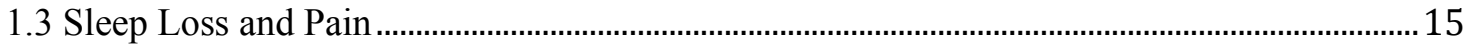

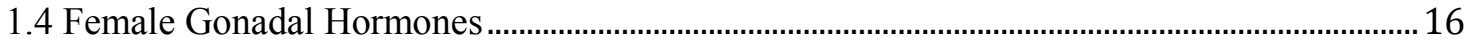

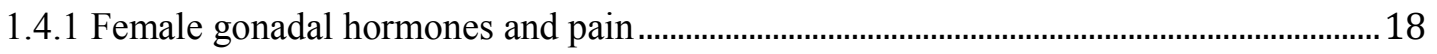

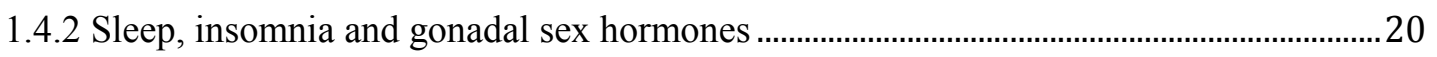

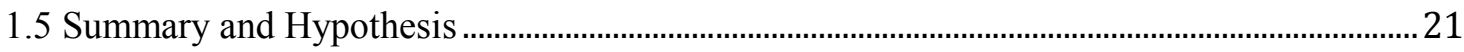

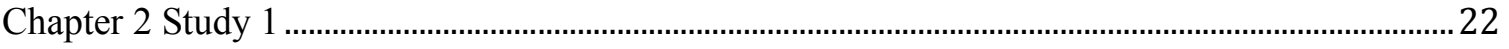

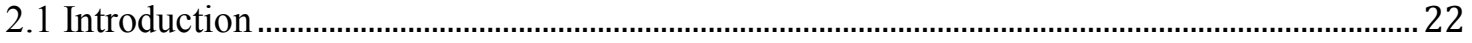

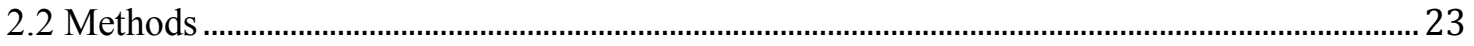

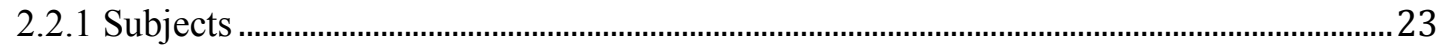

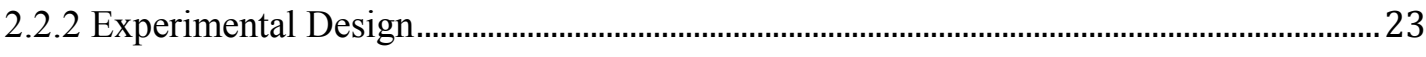

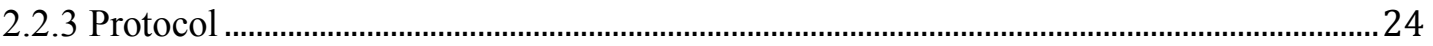

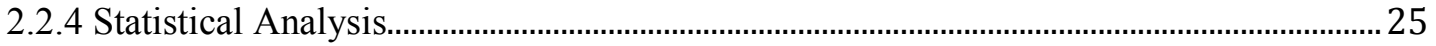

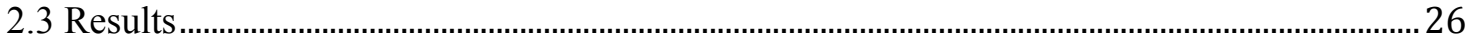

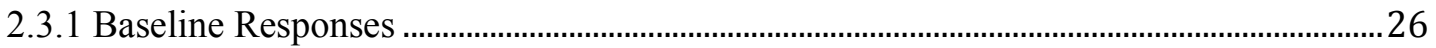

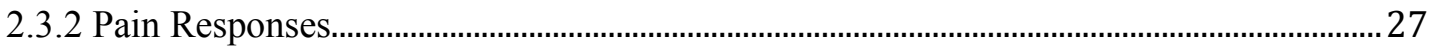

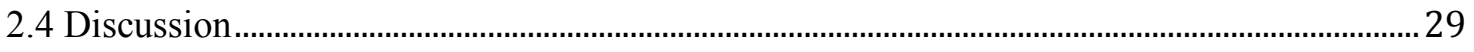




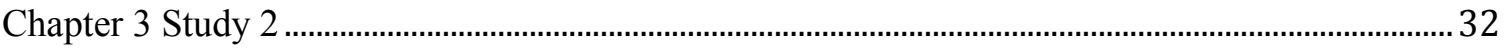

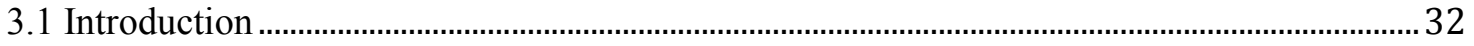

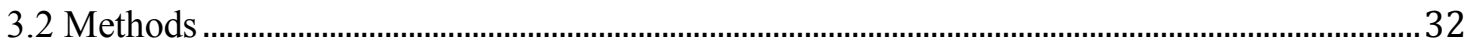

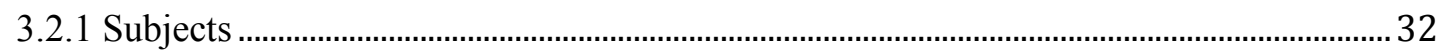

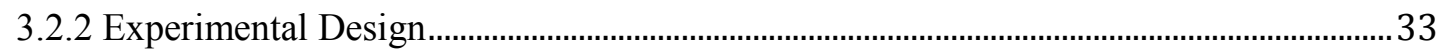

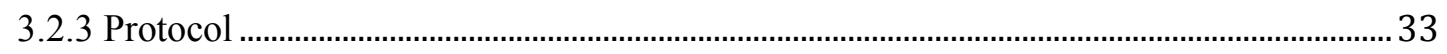

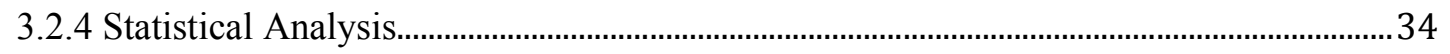

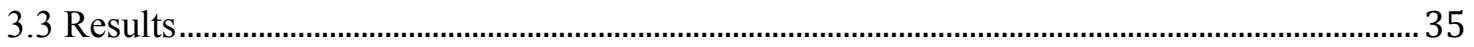

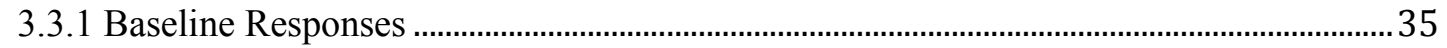

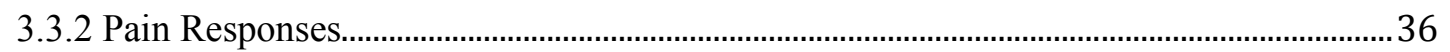

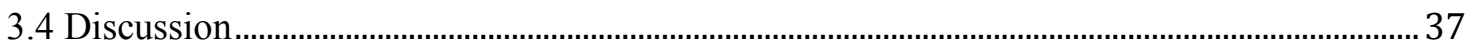

Chapter 4 Summary, Limitations, and Future Directions ........................................................................ 40

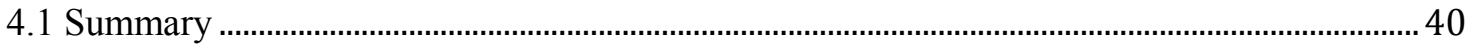

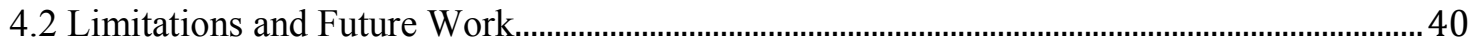

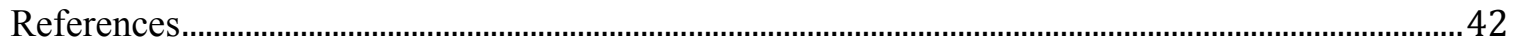

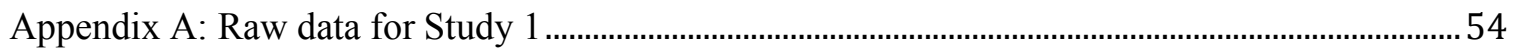

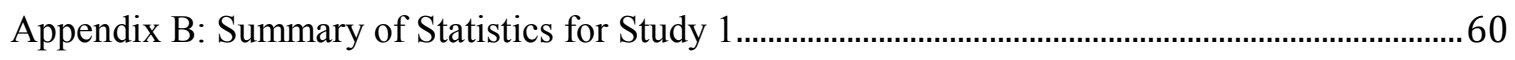

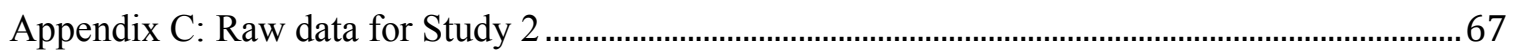

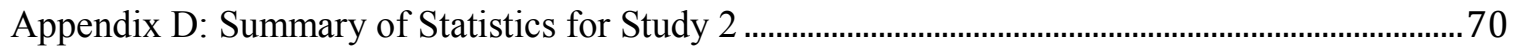

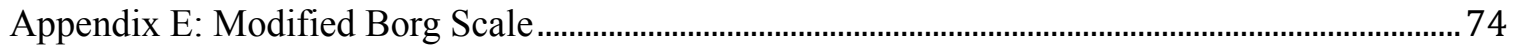




\section{List of Figures}

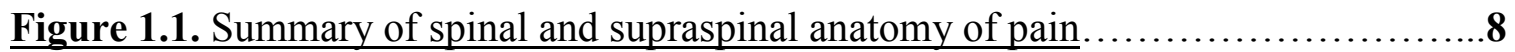

Figure 1.2. Fluctuations in Luteinizing Hormone and the ovarian hormones across the

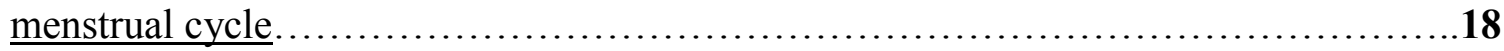

Figure 2.1. Changes in pain intensity during 2-minute cold pressor test following normal sleep and 24-hour total sleep deprivation........................................27

Figure 2.2. Changes in mean and peak pain intensity during 2-minute cold pressor test following normal sleep and 24-hour total sleep deprivation. .28

Figure 2.3. Mean changes in pain intensity during 2-minute cold pressor test (CPT) in

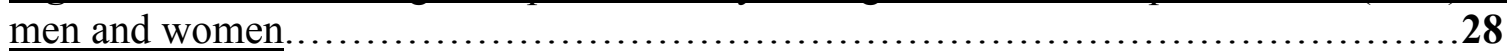

Figure 3.1. Changes in pain intensity during 2-minute cold pressor test during EF and ML phases of the menstrual cycle following 24-hour total sleep deprivation.............36

Figure 3.2. Changes in mean and peak pain intensity during 2-minute cold pressor test during EF and ML phases of the menstrual cycle following 24-hour total sleep

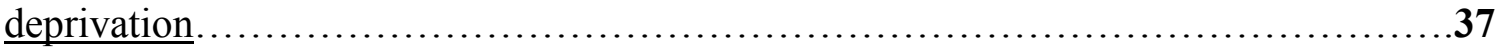




\section{List of Tables}

Table 1.1. Summary of the three prominent theories of pain $\ldots \ldots \ldots \ldots \ldots \ldots \ldots \ldots \ldots \ldots$

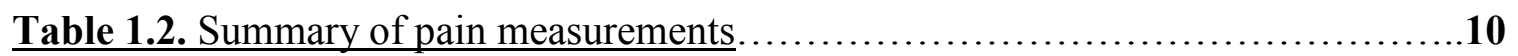

Table 2.1. Baseline values for men and women following normal sleep and 24-hour total

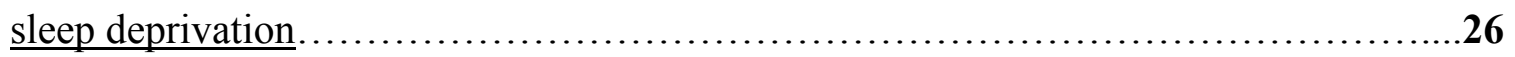

Table 3.1. Resting variables for early follicular and mid-luteal testing sessions..........35 


\section{Acknowledgements}

I would like to thank my family for always providing me with support in my academic pursuits. I would like to thank my advisor Dr. Jason Carter for giving me with the opportunity to explore scientific research. It has taken me a while to find my career path and the experiences in your lab have provided me with a strong foundation for my future endeavors. I would like to thank Dr. John Durocher for all the help he has provided over the last few years. My experience in the lab was greatly enhanced by working with you. I would like to thank Dr. Thomas Drummer for his guidance. I would also like to thank Dr. Chen for his patience while I finished my thesis. I look forward to working in his lab and earning my doctorate degree in the next few years.

I would like to thank all of the research assistants who have worked in the lab including Michelle King, Kristen Reed and Taylor Kaurala. I would also like to thank my fellow graduate students for sharing my experiences. Dr. Chris Schwartz was instrumental in helping me learn the operations of the lab. Sarah Stream and Jennifer Witting provided a sounding board for ideas. I would like to say a special thank you to Huan Yang. Huan and I have been partners in many pursuits over the last few years and her smile and cheerfulness under all circumstances always made my day more enjoyable.

Finally I would like to thank Terry Anderson and Shannon Brodeur for always helping with everything. Your support for graduate students is amazing and we would not be as successful without your help. 


\section{List of Abbreviations}

$\begin{array}{ll}\text { NS } & \text { Normal Sleep } \\ \text { TSD } & \text { 24-hour Total Sleep Deprivation } \\ \text { CPT } & \text { Cold Pressor Test } \\ \text { EF } & \text { Early Follicular phase of Menstrual Cycle } \\ \text { ML } & \text { Mid-Luteal phase of Menstrual Cycle } \\ \text { REM } & \text { Rapid Eye Movement } \\ \text { EEG } & \text { Electroencephalogram } \\ \text { EMG } & \text { Electromyogram } \\ \text { EOG } & \text { Electrooculogram } \\ \text { SWS } & \text { Slow wave sleep } \\ \text { GnRH } & \text { Gonadotropin releasing hormone } \\ \text { LH } & \text { Luteinizing hormone } \\ \text { FSH } & \text { Follicle stimulating hormone } \\ \text { SAP } & \text { Systolic arterial pressure } \\ \text { DAP } & \text { Diastolic arterial pressure } \\ \text { MAP } & \text { Mean arterial pressure } \\ \text { BMI } & \text { Body mass index } \\ \text { DNIC } & \text { Diffuse Noxious Inhibitory Control }\end{array}$




\begin{abstract}
Little or poor quality sleep is often reported in patients suffering from acute or chronic pain. Conversely, sleep loss has been known to elevate pain perception; thus a potential bi-direction relationship exists between sleep deprivation and pain. The effect of sleep deprivation on the thermal pain intensity has yet to be determined, furthermore, sex differences in pain have not been examined following sleep deprivation. There is also a higher prevalence of insomnia in women, and reports indicate that sleep quality is diminished and pain sensitivity may be greater during high hormone phases of the menstrual cycle. In Study 1 we examined the effects of 24-hour total sleep deprivation (TSD) on pain intensity during a 2-minute cold pressor test (CPT). We hypothesized that TSD would augment thermal pain intensity during CPT and women would demonstrate an elevated response compare to men. In Study 2 we investigated the effects of menstrual phase on pain intensity during CPT following TSD. We hypothesized that pain intensity would be augmented during the mid-luteal (ML) phase of the menstrual cycle. In Study 1, pain intensity was recorded during CPT in 14 men and 13 women after normal sleep (NS) and TSD. Pain intensity responses during CPT were elevated in both conditions; however, pain intensity was augmented ( $\sim \Delta 1.2$ a.u.) following TSD. When analyzed for sex differences, pain intensity was not different between men and women in either condition. In Study 2, pain intensity was recorded during CPT in 10 female subjects during the early follicular (EF) and ML phases of the menstrual cycle after TSD. Estradiol and progesterone levels were elevated during the ML phase, however, pain intensity was not different between the two phases. We conclude that TSD significantly augments pain intensity during CPT, but this response is not sex dependent. We further demonstrate that the collective effect of TSD and elevated gonadal hormone concentrations do not result in a differential pain response during the EF and ML phases of the menstrual cycle. Collectively, sleep loss augments pain intensity ratings in men and women and may contribute to sleep loss in painful conditions.
\end{abstract}




\section{Chapter 1 Literature Review}

\subsection{Introduction to Pain}

Epidemiological studies indicate that approximately one quarter of United States (US) residents suffer from some type of pain (Krueger \& Stone, 2008; Toblin et al., 2011). A recent study examining the economic cost of pain in terms of health care and lost productivity in the US estimated the total cost of pain was somewhere between $\$ 560$ and $\$ 635$ billion when referenced to the year 2010 (Gaskin \& Richard, 2012). Therefore, understanding the processes involved in pain sensation, and developing new strategies for the management of pain are paramount for society. The International Association for the Study of Pain describes pain as "an unpleasant sensory and emotional experience associated with actual or potential tissue damage, or described in terms of such damage" (Merskey, 1991). This chapter will examine the theories of pain along with an introduction to the anatomy and physiology involved in the sensation of pain.

\subsubsection{Pain Theory}

Human understanding of pain and the mechanisms that bring about a painful response has varied greatly since the times of the ancient Greek civilizations. Beginning around the end of the $19^{\text {th }}$ century researchers began to focus their efforts on identifying the mechanisms contributing to a painful response. Pain theory has been widely debated over the years, and has resulted in three main competing theories.

The specific theory of pain was the first theory to gain almost universal favor among scientists, particularly physiologists. The specific theory of pain is very clear in a physiological sense in that free nerve endings are the receptors of pain. The roots of the specific theory can be traced back to Muller who first proposed a special class of nerves for the sense of feeling (Muller, 1841; Dallenbach, 1939). Von Frey performed pioneering studies in pain sensitivity utilizing punctate stimuli known today as von Frey hairs. Through the use of varying levels of stimuli, Von Frey was able to determine the existence of four types of sensory spots on the skin of humans including warmth, cold, pressure and pain (von Frey, 1894, 1895, 1896; Dallenbach, 1939). The existences of 
pain "spots" lead von Frey to champion the specific theory of pain (Dallenbach, 1939). In 1906 Sherrington noted that the sensation of pain often involved tissue damage or injury and described "noxious stimuli" as any stimulus capable of causing tissue damage or the perception of tissue damage. He also described "nociceptors" as afferents responsible for carrying pain signals (Sherrington, 1947). The specific theory suggests a direct path to the brain and once a stimulus is detected by a receptor, the signals are transmitted to the spinal cord via afferent A-Delta and C fibers and then, directly transmitted to the brain (Erlanger \& Gasser, 1924; Bishop et al., 1933). While the specific theory of pain is quite simple in a physiological sense, it fails to account for the psychological aspects of pain leaving room for competing theories.

The specific theory of pain was readily accepted by physiologists, but the psychologists tended to disagree because the specific theory failed to account for the psychological aspects of pain (Kulpe, 1905; Dallenbach, 1939; Melzack \& Wall, 1965). Goldscheider articulated a theory that indicated that pain sensation is brought about by intense stimulus on non-specific sensory receptors (Goldscheider, 1894; Dallenbach, 1939). Essentially any stimulus such as cold, heat, pressure, light, sound, or smells, given in a large quantity, can cause pain. An extension of this theory was later proposed by Nafe who believe that patterns of stimulation in afferent nerves were responsible for pain (Kenshalo \& Nafe, 1962). Weddell and Sinclair further supported the view that pain is generated from spatial and temporal summation of impulses arising from painful stimuli on non-specific receptors (Sinclair, 1955; Weddell, 1955; Melzack \& Wall, 1965). The major shortcoming of the pattern theory is that evidence indicates that there are multiple forms of specific receptors that encode pain.

In 1962 Melzack and Wall reviewed the theories of pain transmission and articulated the shortcomings of the specific and pattern theories of pain (Melzack \& Wall, 1962). They proposed the "Gate Control Theory of Pain" to account for the shortcomings of both specific and pattern theory (Melzack \& Wall, 1965). The gate theory allows for descending control of painful stimuli and recognizes both physiological and psychological aspects of pain. 
The gate theory proposes that pain signaling arises from many different sizes of fibers, however, not all signals are transmitted to the brain. Briefly, the substantia gelatinosa, located in the dorsal horn, acts as the pre-synaptic gate modulating the activity of both small and large fiber afferents. The input then is projected to the first central transmission or $\mathrm{T}$ cells and further to the brain. The spinal cord constantly received input from small afferent fibers even without specific stimulation. Most large myelinated fibers are silent without stimulation. When a stimulus is applied, the large myelinated fibers are activated and transmit stimuli that open the gate for a short period of time allowing for pain transmission to supraspinal centers. However, the balance of activity between the large and small afferent fibers determines the opening of the gate and sustained opening relies upon the activation of small fibers (Melzack \& Wall, 1965). An example would be putting a flame to your hand. Initially the large myelinated fibers would fire, opening the gate, and transmitting pain. However, the sustained pain feeling after removal of the flame would be from small myelinated and unmelinated fiber activation in response to tissue damage, which holds the gate open and allow for signal transmission. 
Table 1.1. Summary of the three prominent theories of pain.

\begin{tabular}{|c|c|}
\hline $\begin{array}{l}\text { Specific } \\
\text { Theory }\end{array}$ & $\begin{array}{l}\text { - Specific receptors for pain including mechanical, } \\
\text { thermal, and chemoreceptors } \\
\text { - Direct afferent path to the brain }\end{array}$ \\
\hline $\begin{array}{l}\text { Pattern } \\
\text { Theory }\end{array}$ & $\begin{array}{l}\text { - Non-specific receptors } \\
\text { - Any stimulus, given in a large enough quantity, } \\
\text { will cause pain } \\
\text { - Spatial and temporal summation of afferent nerve } \\
\text { activity results in pain }\end{array}$ \\
\hline $\begin{array}{l}\text { Gate } \\
\text { Theory }\end{array}$ & $\begin{array}{l}\text { - Combination of Specific and Pattern Theories } \\
\text { - Pre-synaptic gate in the spinal cord modulates } \\
\text { afferent pain signals } \\
\text { - Large myelinated fiber activity initially opens the } \\
\text { gate in response to a large stimulus allowing } \\
\text { transmission of afferent pain sensation } \\
\text { - Small unmyelinated fiber activity in response to } \\
\text { tissue damage continually holds the gate open } \\
\text { once the stimulus is removed resulting in sustained } \\
\text { pain sensation }\end{array}$ \\
\hline
\end{tabular}

\subsubsection{Anatomy of Pain}

Prior to the $18^{\text {th }}$ century little evidence was available regarding the pathways of the nervous system and their ability to sense pain. Charles Bell proposed that the dorsal and ventral roots in the spinal cord have different functions, and that the ventral root was responsible for motor activity (Bell, 1811; Dallenbach, 1939). The sensory aspect of the dorsal root was demonstrated by Francois Magendie several years later (Magendie, 1822; Dallenbach, 1939). Schiff was the first to distinguish the sense of touch and pain from each other through studies examining spinal cord lesions. He discovered when the gray matter of the spinal cord was severed, pain would not be felt in areas below the incision, but touch remained. In contrast, when the white matter was severed instead of the gray matter, the sense of touch was lost while pain sensation remained intact (Schiff, 1859; Perl, 2011). Schiff was able to conclude that touch and pain involved different pathways within the spinal cord and that pain and temperature sensation crossed the spinal cord to the contralateral side. Following Schiff's conclusions about crossing pathways within the 
spinal tract, several scientists supported his data through observations in animals (BrownSequard, 1868; Perl, 2011) and humans (Gowers, 1877).

Gasser and Erlanger were the first to examine action potentials with the cathode ray oscilloscope (Erlanger \& Gasser, 1922). New research in the electrical properties of nerves allowed for the identification of the fibers responsible for afferent transmission of pain. The visualization of the compound action potential in multifibre nerves demonstrated specific deflections that were attributed to single fibers within the bundle. The A deflection represents the fastest fibers and is attributed to large myelinated fibers (Erlanger \& Gasser, 1924). The C deflection represents the slowest fibers and is attributed to small unmyelinated fibers (Erlanger \& Gasser, 1924; Bishop et al., 1933).

Nociceptors are responsible for sensing painful stimuli and communicating that stimulus to spinal and supraspinal centers for interpretation. One of the first dedicated nociceptors to be discovered were thin-myelinated nerves that required high threshold mechanical stimulation and exhibit an A deflection on the compound action potential (Burgess \& Perl, 1967; Perl, 1968). These fibers have been shown to project to lamina I and laminae V and VI in the ipisilateral dorsal horn (Light \& Perl, 1979). Once the first true nociceptor was discovered, research in the area intensified. Studies identified and demonstrated that nociceptors have a specific response to noxious stimuli including mechanical, heat, pressure, cold and acid (Bessou \& Perl, 1969; Kumazawa \& Perl, 1977; Lynn \& Carpenter, 1982).

Most nociceptors are polymodal in that they respond to more than one type of stimuli. There are two distinct types of nociceptors including myelinated A-delta fibers, and unmylinated $\mathrm{C}$ fibers (Perl, 2011). A-Delta fibers have a medium diameter and are responsible for the fast pain response and are further subdivided into two groups. Type I are known as high threshold mechanical receptors and are involved in sensing mechanical, chemical, and very high threshold heat stimuli (Basbaum et al., 2009). Type II A fibers have a high mechanical threshold, but a low heat threshold compared to type I fibers. Unmelinated C fibers carry the "slow" pain or secondary response (Basbaum et al., 2009). The most common $\mathrm{C}$ fibers are mechanical/heat receptors labeled CMH. Other populations are heat sensitive, mechanical insensitive nociceptors labeled silent 
nociceptors that also respond to chemical stimuli such as capsaicin and histamine (Schmidt et al., 1995). C fiber nociceptors also respond to cold stimuli (Bessou \& Perl, 1969). Nociceptors that respond to cold stimuli below $10{ }^{\circ} \mathrm{C}$ are different from cold thermoreceptors that demonstrate activity between 10 and $40{ }^{\circ} \mathrm{C}$. Cold thermoreceptors are responsible for maintaining proper skin temperature and allow for thermal sensation (Kenshalo \& Duclaux, 1977). Medium diameter myelinated A fibers and unmyelinated C fibers transmit afferent information from cold thermoreceptors (Hensel et al., 1974).

Sensory input enters the spinal cord through the dorsal root. The spinal cord has 3 distinct areas. The posterior horn is composed of laminae I-VI, the lateral horn consists only of Lamina VII, and the anterior horn is comprised of laminae VIII-IX. A-delta afferents project to lamina $\mathrm{I}$ and $\mathrm{V}$, whereas $\mathrm{C}$ fibers nociceptors project primarily to lamina I (Perl, 2011). Nociceptor afferent nerves enter the spinal cord through the dorsal root. They synapse with secondary afferent nerves and excitatory signals from the primary nociceptor afferents causes action potentials in the secondary afferents, which carry the pain signal to the brain through the white matter of the spinal cord. The spinothalmic tract is involved in carrying pain signals to the thalamus (Perl, 2011), while the spinoreticulothalmic tract terminates in the brainstem (Basbaum et al., 2009). Pain signals from the thalamus and brainstem are sent to higher brain structures including the somatosensory cortex, anterior cingulate gyrus and insular cortex among others since it is important to note that there is no one center for pain processing in the brain (Apkarian et al., 2005). 


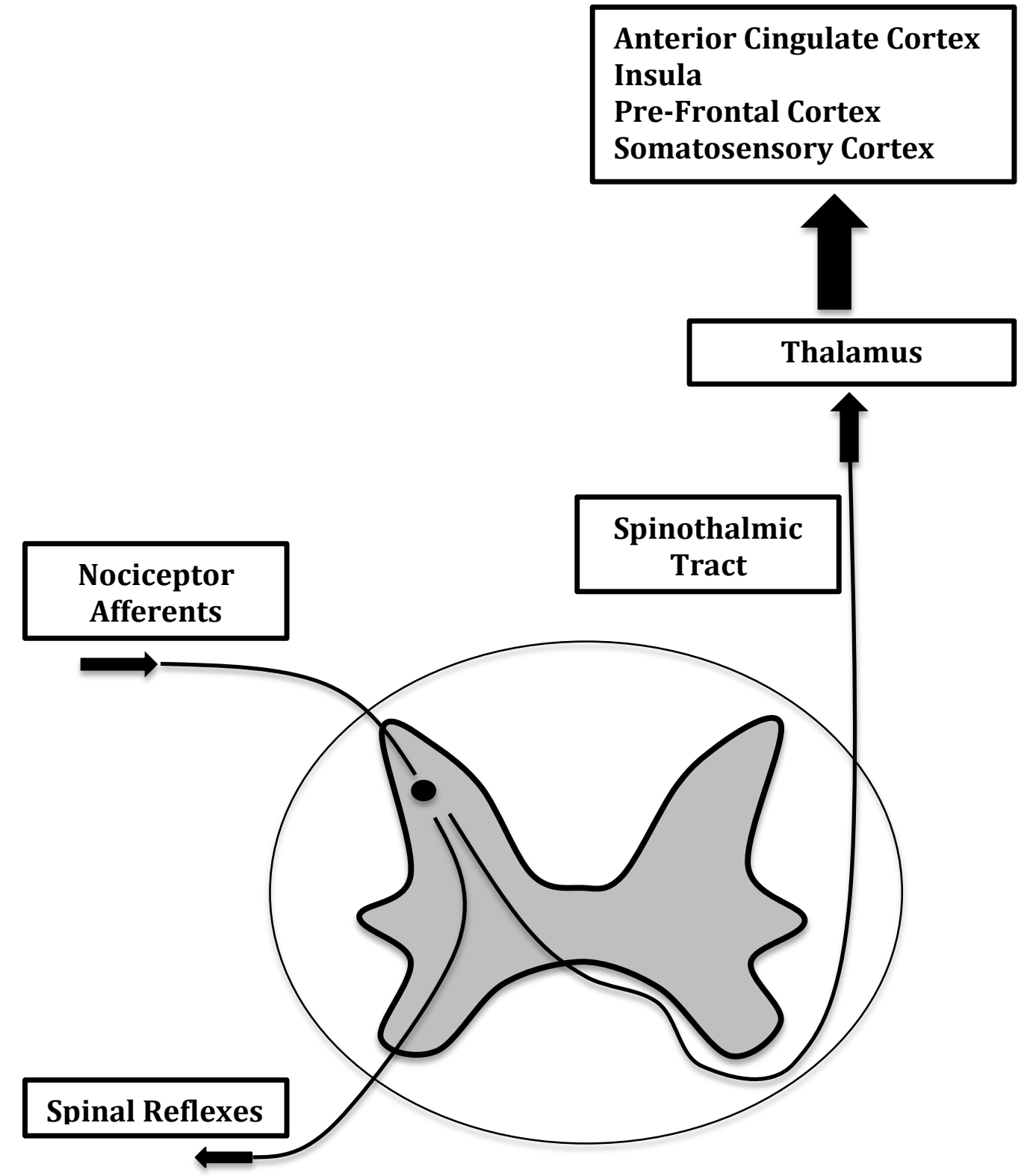

Figure 1.1. Summary of spinal and supraspinal anatomy of pain. Afferent nerve activity enters the spinal cord in the dorsal horn and is transmitted to the thalamus through the spinothalmic tract. Adapted from Basbaum et al., (2009) 


\subsubsection{Sex Differences in the Perception of Pain}

Epidemiological studies suggest that women report more chronic pain than men (Crook et al., 1984; Reisbord \& Greenland, 1985; Unruh, 1996; Fillingim et al., 2009). Laboratory-induced pain also demonstrates sex differences, but the results vary based on the experimental approach. Studies utilizing mechanical stimuli consistently demonstrate that women have an enhanced pain sensitivity compared to men (Buchanan \& Midgley, 1987; Brennum et al., 1989; Jensen et al., 1992). Pain induced by electric stimulation has also demonstrated sex differences (Notermans \& Tophoff, 1967; Robin et al., 1987; Rollman \& Harris, 1987), although several studies have reported no difference (Neri \& Agazzani, 1984; Ayesh et al., 2007). A substantial number of studies support the conclusion that women have a greater sensitivity to heat pain compared to men. In a review of the literature, Fillingim et al. reported that 12 of 17 studies examining heat pain threshold and 15 of 16 studies examining heat pain tolerance demonstrated sex differences with women reporting more sensitivity to heat pain (Fillingim et al., 2009). Cold pain has also demonstrated sex differences and Fillingim et al. noted that 6 of 9 studies for pain threshold, 14 of 15 studies for pain tolerance, and 13 of 16 studies for pain intensity demonstrated sex differences with women reporting higher pain than men (Fillingim et al., 2009). Although experimental pain may be induced by any number of paradigms, evidence consistently suggests that women have a higher sensitivity to pain than men. 
Table 1.2. Summary of pain measurements.

\begin{tabular}{c|c|l}
\hline Measurement & \multicolumn{1}{c}{ Definition } & \multicolumn{1}{c}{ Description } \\
\hline Pain Threshold & $1^{\text {st }}$ sensation of pain & $\begin{array}{l}\text { Level of mechanical or } \\
\text { thermal stimuli required to } \\
\text { induce pain. }\end{array}$ \\
\hline \multirow{5}{*}{ Pain Tolerance } & $\begin{array}{c}\text { Point where pain } \\
\text { stimulus become } \\
\text { unbearable }\end{array}$ & $\begin{array}{l}\text { Measured during a sustained } \\
\text { protocol such as the cold } \\
\text { pressor test or ischemia } \\
\text { protocol. Measure of } \\
\text { tolerance will occur when } \\
\text { subjects stops the test. }\end{array}$ \\
\hline Pain Intensity & $\begin{array}{c}\text { Level of pain rated } \\
\text { on a visual analog } \\
\text { scale }\end{array}$ & $\begin{array}{l}\text { Measured during a sustained } \\
\text { protocol such as the cold } \\
\text { pressor test or ischemia } \\
\text { protocol. Subjects rate their } \\
\text { level of pain at specific time } \\
\text { points. }\end{array}$ \\
\hline
\end{tabular}

\subsection{Sleep}

Modern human sleep research began with the first study examining brain activity with an electroencephalogram (EEG) during sleep. Loomis et al described varying activity in the EEG during sleep in humans and abolished the thought that sleep was one homogenous experience within the brain. Included in their analysis was a description of five different types of EEG stages as sleep progressed through the night (Loomis et al., 1937). This publication was the first to separate the different stages of sleep based on EEG. Aserinsky \& Kleitman (1953) were the first to report the existence of rapid eye movements (REM) during particular periods of sleep. REM sleep periods occurred periodically throughout the night, with subsequent periods lasting a shorter time than previous. They also reported that respiratory rate and heart rate increased during REM sleep, and further concluded that dreaming occurred during the periods of REM sleep (Aserinsky \& Kleitman, 1953). Dement and Kleitman expanded the early work on REM 
sleep by observing EEG during REM stages and reporting fast frequency, low voltage EEG activity during REM periods. They also reported that NonREM and REM sleep alternate throughout a given session of sleep, and suggested new sleep stages that clearly separated REM and NonREM sleep (Dement \& Kleitman, 1957). In 1968 Rechtschaffen and Kales proposed a comprehensive scoring system to differentiate the stages of sleep based on polysomnography recordings (Rechtschaffen \& Kales, 1968). Polysomnography recordings during sleep include EEG, electrooculogram (EOG), and electromyogram (EMG), and are scored based on 30-second epochs of data.

\subsubsection{Sleep Stages (Rechtschaffen and Kales)}

Wake stage displays mixed frequency, low voltage activity in the EEG in the range of $2-7 \mathrm{~Hz}$. Also, alpha activity of $8-13 \mathrm{~Hz}$ occurs greater than $50 \%$ of the recording. As expected with wakeful movement, there is usually elevated activity recorded via EMG (Rechtschaffen \& Kales, 1968).

Stage 1 sleep is a transition state between wakefulness and other stages of sleep typically lasting between 1 and 7 minutes. It also occurs following slight arousals or body movements during sleep. The EEG in Stage 1 sleep displays a mixed frequency of low voltage activity, but alpha activity occurs less than $50 \%$ of the recording. There are also slow eye movements and less EMG activity than when the patient is awake (Rechtschaffen \& Kales, 1968).

Stage 2 sleep is best characterized by the observance of sleep spindles and $\mathrm{K}$ complexes on the EEG with high frequency, medium voltage waves. Sleep spindles are short bursts, lasting about a half second, with a frequency of 12-14 Hz. K complexes are large waves with a sharp negative and positive peaks lasting not longer than half a second (Rechtschaffen \& Kales, 1968).

Stage 3 sleep occurs when $20-50 \%$ of the EEG displays waves lower than $2 \mathrm{~Hz}$ and amplitude greater than 75 microvolts. Occasionally sleep spindles and $\mathrm{K}$ complexes are noted in stage 3 sleep (Rechtschaffen \& Kales, 1968). 
Stage 4 sleep is scored when EEG waves occur at a frequency less than $2 \mathrm{~Hz}$ with amplitudes greater than 75 microvolts are noted more in more than $50 \%$ of the scoring epoch. The combination of stage 3 and 4 sleep is collectively termed slow wave sleep (SWS) (Rechtschaffen \& Kales, 1968).

REM sleep displays mixed frequency, low voltage EEG activity similar to the alpha activity in stage 1 sleep. There is also specific wave activity termed "saw tooth" on the EEG that are only noted in REM sleep. Sleep spindles and K complexes are not noted during REM sleep and there is very low EMG activity (Rechtschaffen \& Kales, 1968).

\subsubsection{Sleep Stages (AASM)}

In 2007 the American Academy of Sleep Medicine sought to re-examine the stages of sleep due to the advancements in technology since Rechtschaffen and Kales published their sleep scoring method. They determined that loss of alpha activity is the best way to define the transition from wake to Stage 1 sleep. They also combined stage 3 and 4, as defined by Rechtschaffen and Kales, into one stage thereby combining the two SWS stages. They also put forth new rules to clearly define the presence of REM sleep. The new sleep stages according to the AASM are now labeled Stage W (wake), Stage N1, Stage N2, Stage N3, and Stage R (REM) (Silber et al., 2007).

In healthy young adult humans, sleep occurs in cycles throughout the night. Stage 1 sleep begins the first cycle in the transition from waking and lasts several minutes before stage 2 sleep begins. Stage 2 sleep can occur for approximately 10 to 25 minutes as the transition from light sleep in stage 1 to deeper sleep begins. The end of stage 2 sleep is signaled by the appearance of low frequency waves as deep slow wave sleep starts to predominate. Stage 3 sleep is a relatively short transitory stage into the long lasting (20-40 min) stage 4 slow wave sleep. REM sleep brings about a slightly higher level of consciousness and in the first cycle of the night it will only last for up to 5 minutes. Following REM, sleep stage 2 sleep occurs, and the cycle will repeat throughout the night. Sleep cycles take approximately 80-90 minutes to complete, and with more 
cycles in a given night, time spent in SWS sleep will decrease, while time spent in stage 2 and REM will increase (Carskadon \& Dement, 1994).

\subsubsection{The Two-Process Model of Sleep Regulation}

Two separate yet equally important processes govern sleep (Borbely, 1982; Daan et al., 1984). The circadian process for sleep (Process C) is considered sleep independent and is primarily regulated by the suprachiasmatic nucleus in the hypothalamus. The physiological process for sleep (Process $\mathrm{S}$ ) is sleep dependent and can be represented by the activity of an electroencephalogram (EEG). The interaction between these two systems determines when we feel the need to sleep, the length of sleep, and the progression through the sleep stages (Borbely, 1982; Daan et al., 1984; Achermann, 2004).

Most of life on earth has some dependence on the light/dark cycle that occurs in each 24-hour period as the earth rotates on its axis. The word circadian in a Latin sense essentially means around the day in reference to a 24-hour period of time. Evidence suggests that the generator of the circadian rhythm is the hypothalamic suprachiasmatic nucleus (SCN) (Moore \& Eichler, 1972; Meijer \& Rietveld, 1989; Ralph et al., 1990). The SCN responds to changes in the light dark cycle by receiving input from retinal ganglion cells that have axon projections to the SCN (Berson et al., 2002). The influence of the circadian system on sleep pressure is associated with the release of melatonin from the pineal gland (Dijk 1997, Lavie 1997) with sleep occurring during times of melatonin release into the bloodstream. However the SCN has efferent projections to multiple systems that can influence sleep pressure including the adrenergic, orexin, and serotonergic systems. Early studies also indicate that sleep propensity is also associated with the variance in body temperature with greater sleep pressure occurring with core body temperature is decreasing (Kleitman, 1933; Murray et al., 1958).

Walter Cannon developed the term homeostasis essentially meaning a propensity of a body system to regulate the environment in a stable condition (Cannon, 1939). In terms of sleep, homeostatic regulation applies to the length and depth of sleep over a period of time. From the most basic standpoint, one might assume that as you are sleep 
deprived you will compensate via extended sleep time to ensure sleep homeostasis. In contrast, studies have shown that recovery sleep time from extended periods of sleep deprivation do not properly account for the lost sleep. One study demonstrated that following 90 hours of sleep deprivation, recovery sleep lasted 10 hours (Blake \& Gerard, 1937) while another reported 264 hours of sleep deprivation followed by 14.4 hours of recovery sleep (Gulevich et al., 1966). These studies indicate that full recovery from long episode of sleep deprivation do not necessarily come from the length of recovery sleep. While the body has mechanisms to ensure homeostasis, other areas of sleep structure play a role in recovery from sleep loss than just extended recovery sleep time.

Researchers began to examine the quality of sleep to determine if parameters within sleep structure were involved in the recovery from sleep loss. Several studies have also examined sleep onset, latency, and stage progression during sleep restriction protocols. Sleep restriction refers to short sleep times over multiple days. Evidence indicates that as sleep restriction progresses, subject's level of perceived sleepiness increases, while sleep latency, stage 1, stage 2 and REM sleep are dramatically reduced, with the exception of the SWS stages, which remain unaltered (Webb \& Agnew, 1975; Carskadon \& Dement, 1981). These results indicate that SWS may be the key to homeostatic recovery from sleep loss. SWS is more prominent in sleep cycles in the beginning of the night (Dement \& Kleitman, 1957) and enhanced following sleep deprivation (Berger \& Oswald, 1962). Further studies indicate that excess sleep (Feinberg et al., 1980) or napping (Karacan et al., 1970) can cause a reduction in SWS in the subsequent night after sleep deprivation. Spectral analysis of EEG in the low frequency range is considered a better indicator of SWS than scoring based on stages. Borbely et al. demonstrated that SWS, as quantified by power spectral analysis, was augmented during recovery sleep following 40.5 hours of sleep deprivation (Borbely et al., 1981). SWS is shortened following extended sleep, but enhanced following sleep deprivation, indicating it is a primary variable in the homeostatic model of sleep and can be used to indicate the propensity towards sleep in humans.

In order to present the two-process model of sleep, the assumption must be made that Process C and Process S are independent of one another (Borbely, 1982; Daan et al., 
1984). The best marker to visualize Process $C$ is the rhythmic changes in body temperature throughout the day. Body temperature starts to descend in the evening illustrating an increase in the circadian propensity for sleep. When body temperature is at its minimum point, the circadian pressure for sleep is at a maximum. Process $\mathrm{S}$, as defined as the need for SWS in a homeostatic sense, is at a minimum at waking. Process $\mathrm{S}$ ascends during the day as the pressure for SWS increases and reaches a maximum when sleep is begun.

\subsection{Sleep Loss and Pain}

There is evidence from epidemiological studies indicating a link between chronic pain and sleep loss (Pilowsky et al., 1985; Atkinson et al., 1988; Moffitt et al., 1991; Morin et al., 1998; Power et al., 2005). Pain is often considered the main variable resulting in the loss of total sleep time, and non-restorative sleep, in many different types of chronically painful conditions. Evidence from cross-sectional studies utilizing polosomnography to examine sleep in patients with pain helps to further establish this link (Wittig et al., 1982; Raymond et al., 2001).

Multiple studies have examined pain following total sleep deprivation of varying lengths. The association between sleep loss and pain was first reported in 1934. Cooperman et al. published an uncontrolled study reporting a decrease in threshold for cutaneous pain as measured with von Frey hairs in six male subjects during a 60 hour sleep deprivation protocol (Cooperman et al., 1934). In more recent years, the observations made by Cooperman have been supported using a variety sleep loss paradigms and methods of stimuli in humans (Onen et al., 2001; Kundermann et al., 2004; Roehrs et al., 2006; Smith et al., 2007).

Studies have also sought to examine the effects of selective sleep stage deprivation on the pain response in subjects with fibromyalgia. In two separate studies, Moldofsky et al examined pain evoked by dolorimetry after selective sleep stage deprivation. These studies provided evidence indicating that pain in patients suffering from fibromyalgia is elevated following stage 4 sleep deprivation (Moldofsky et al., 1975), but unaltered following REM sleep deprivation (Moldofsky \& Scarisbrick, 1976). 
Several studies attempted to replicate the findings of Moldofsky but failed to see the same results. In a sample of 19 subjects (13 treatment, 6 control), Older et al. failed to find any difference in pain threshold assessed by dolorimetry either within or between groups following stage 4 sleep deprivation (Older et al., 1998). In contrast, Lentz et al. reported a decrease in pain threshold following slow wave sleep deprivation (stage $3 \& 4$ ) in a sample of 12 women. It is important to note that this study did not include a control group (Lentz et al., 1999). Whether in normal healthy subjects, or in patients suffering from fibromyalgia, sleep loss and sleep deprivation augment the pain response to many different types of stimulation in humans.

\subsection{Female Gonadal Hormones}

The female reproductive system involves cyclic changes in the ovaries and the uterus with each cycle lasting for approximately 28 days in normal non-pregnant females. The ovaries have a dual role in that they are responsible for production of the ovum and ovarian steroids. The ovaries contain the primordial follicles that will ultimately become the oocyte. In each cycle, several primordial follicles will begin the process of maturation into primary and then secondary follicles.

The beginning of the ovarian and uterine cycles occurs with the release of gonadotropin releasing hormone $(\mathrm{GnRH})$. GnRH is secreted by the hypothalamus (Clayton, 1989) and operates by signaling the release of follicle-stimulating hormone (FSH) and luteinizing hormone (LH) from the anterior pituitary gland (Schally et al., 1971). This period is termed the follicular phase and will last approximately 14 days. During the follicular phase the secondary follicles begin to secrete estrogen and a single secondary follicle will become the mature graffian follicle (McNatty et al., 1975). The graffian follicle consists of several layers including the outer layer or theca externa, the inner layer or theca interna and a secretory layer termed the granulosa layer (Sanyal et al., 1974). Estrogens will inhibit the release of further FSH and LH from the anterior pituitary and the less developed follicles will cease development (Goldenberg et al., 1972). Circulating estrogen in the blood also signals the uterus and the repair of the endometrium will begin. The stratum basalis begins mitosis producing the stratum 
functionalis resulting in a thickening of the endometrium. As the thickening of the endometrium occurs, endometrial glands are developed and the arterioles are extended into the stratum functionalis.

Ovulation will occur approximately 14 days into the cycle. Estrogen will reach a critical peak and, instead of inhibiting FSH and LH, it exerts positive feedback and causes the release of $\mathrm{GnRH}$ from the hypothalamus, which promotes a large release of LH and FSH (Goldenberg et al., 1972). The "LH surge" will cause the graffian follicle to rupture and the secondary oocyte is released. The Luteal phase begins with expulsion of the oocyte from the graffian follicle. After exclusion of the oocyte, the graffian follicle undergoes the process of Luteinization whereby the therca interna cells and the granulosa cells mix forming first, the corpus hemorrhagicum, and then the corpus luteum. The corpus luteum secretes a moderate amount of estrogen, but primarily secretes progesterone (McNatty et al., 1979). The corpus luteum will degrade in approximately 2 weeks if fertilization of the oocyte does not occur and levels of estrogen and progesterone will fall. The cells in the stratum functionalis of the endometrium will die and fall off resulting in menstrual flow. Following menstruation, the cycle will repeat. Figure 1.1 demonstrates the relative hormonal fluctuations during the menstrual cycle. Studies examining the effects of menstrual phase often will compare the early follicular (EF) and mid-luteal (ML) phases since these two phases allow for the largest difference in hormone levels. 


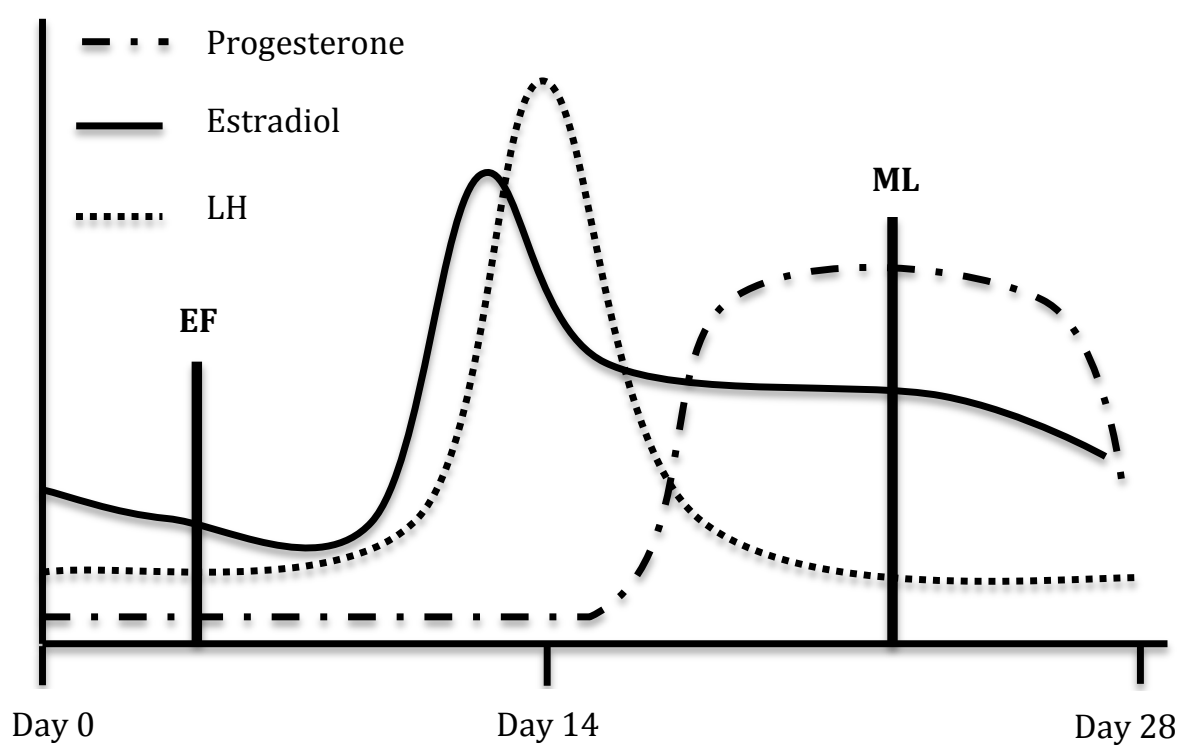

Figure 1.2. Relative fluctuations in Luteinizing Hormone (LH) and the ovarian hormones Estradiol, and Progesterone across the menstrual cycle. EF, early follicular phase; ML, Mid-Luteal phase.

\subsubsection{Female gonadal hormones and pain}

The theory that menstrual cycle phase and sex hormone levels might alter the perception of experimentally induced pain in humans can be traced back to 1933 . Herren (1933) measured pressure pain threshold during three separate time points during the menstrual cycle. The pre-menstruation measurement was taken 5 days prior to menstruation, the inter-menstruation measurement was taken within 3 days following the cessation of menstruation, and the post-menstruation measurement was recorded two weeks following the start of the last menstruation period. The results of the study indicated that pressure pain threshold was decreased in the pre-menstrual phase indicating an elevated sensitivity to pain. While the study failed to measure sex hormone concentration, they attributed their results to the higher hormone levels preceding menstruation. Robinson \& Short (1977) examined the rhythmicity of pressure pain threshold on the breasts and noted that the peak occurred during pre-menstruation or 
menstruation. Other studies that have measured pain in response to pressure stimuli have noted that pain tolerance has been increased in the follicular phase (Kuczmierczyk \& Adams, 1986) while others have demonstrated no difference (Amodei \& Nelson-Gray, 1989). Straneva et al. (2002) measurement of pain tolerance and threshold using other stimulus modalities has brought mixed results. Ischemic pain tolerance and threshold have been demonstrated mixed results with some studies reporting an elevated pain response during the follicular phase (Fillingim et al., 1997; Pfleeger et al., 1997) but others report no difference (Amodei \& Nelson-Gray, 1989; Sherman et al., 2005; Klatzkin et al., 2010)

Studies examining thermal pain during the different phases of the menstrual cycle have demonstrated little difference between phases to heat pain (Fillingim et al., 1997; Granot et al., 2001; Klatzkin et al., 2010). The cold pressor test has been used to study pain throughout the menstrual cycle and Hapidou \& De Catanzaro (1988) reported a lower pain threshold during the luteal phase, but others have reported no difference in pain tolerance or threshold between phases (Veith et al., 1984; Klatzkin et al., 2010). However, ratings of pain intensity during the cold pressor test may provide a closer approximation to clinical pain, and the studies examining pain intensity based on a visual analog scale have reported elevated pain during the luteal phase (Hapidou \& De Catanzaro, 1988; Stening et al., 2007). Furthermore, Stening et al. (2007) demonstrated that rising progesterone levels with a static estradiol increased pain indicating the potential role progesterone serves in altering the pain response during the menstrual cycle.

Although not all studies involving experimentally induced pain have reported differences between phases of the menstrual cycle, studies reporting differences all report an increase in pain sensitivity during the low hormone follicular phase. The conflicting results may be due to in part stimulus modality or the timing of the menstrual cycle causing differences in when subjects were tested during the menstrual cycle. 


\subsubsection{Sleep, insomnia and gonadal sex hormones}

Insomnia is a disorder of hyper-arousal and is characterized by difficulty falling asleep, sleeping, or getting restorative sleep (Roth, 2007). Evidence suggests that approximately $30 \%$ of the population may suffer from insomnia (Health, 2005). Insomnia has significant consequences and can severely impact quality of life in effected individuals. Insomnia has been linked to an increased risk for the development of hypertension (Vgontzas et al., 2009a), diabetes (Vgontzas et al., 2009b), anxiety disorders and depression (Neckelmann et al., 2007). Women are more likely to report insomnia (Klink et al., 1992; Soares, 2005; Sivertsen et al., 2009) and one potential contributing factor in the menstrual cycle.

Studies suggest that subjective ratings of sleep quality are decreased during the Luteal phase of the menstrual cycle (Patkai et al., 1974; Manber \& Bootzin, 1997; Shechter et al., 2010). Despite the evidence indicating lesser quality sleep during the luteal phase, studies examining polysomnography across menstrual phase demonstrate little difference in sleep onset latency, slow wave sleep and sleep efficiency between

phases (Driver et al., 1996; Baker et al., 2004). Several studies demonstrate that REM sleep is decreased during the ML phase (Driver et al., 1996; Shechter et al., 2010) indicating alterations in the circadian process for sleep in the ML phase.

Core body temperature demonstrates a diurnal rhythm with a maximum during the day and a minimum during the night and may be attributed to the release of melatonin (Cagnacci et al., 1992). The propensity for sleep is highest when core body temperature reaches the daily minimum (Murray et al., 1958; Borbely, 1982). Evidence demonstrates that the menstrual cycle effects core body temperature resulting in a blunted nocturnal decline during the luteal phase (Lee, 1988; Cagnacci et al., 1992; Cagnacci et al., 1996; Shibui et al., 2000). The blunted nocturnal body temperature during the luteal phase of the menstrual cycle indicates a disruption in the circadian process of sleep (Shibui et al., 2000) that has implications for the decrease in sleep quality reported during the luteal phase. 


\subsection{Summary and Hypothesis}

Pain and sleep share a complex relationship that appears to be bi-directional. Chronic pain often results in poor quality sleep, or total loss of sleep, and yet, it's been widely reported that sleep loss heightens sensitivity to pain. Studies examining pain following sleep deprivation have not examined pain intensity during a sustained protocol. Study 1 examines the effects of 24-hour total sleep deprivation on ratings of pain intensity during the cold pressor test in men and women. We hypothesized that 24hour total sleep deprivation would augment pain intensity. Evidence suggests that women are more sensitive to painful stimuli, therefore, we further hypothesized that ratings of pain intensity would be higher in women compared to men. Insomnia is more prevalent in women compared to men and the menstrual cycle may play a role in mediating sleep loss in women. Gonadal sex hormones levels fluctuate during the menstrual cycle and may also contribute to alterations in the pain response across menstrual phase. Study 2 examines pain intensity during the early follicular and midluteal phases of the menstrual cycle in females. We hypothesized that pain intensity would be augmented during the ML phase of the menstrual cycle following 24-hour total sleep deprivation in females. 


\section{Chapter 2 Study 1}

\subsection{Introduction}

Patients suffering chronic pain report poor quality sleep and loss of sleep time (Wittig et al., 1982; Smith et al., 2000). However, studies report that sleep loss leads to hyperalgesia and an augmentation of pain (Cooperman et al., 1934; Kundermann et al., 2004; Roehrs et al., 2006). There is considerable evidence indicating sex differences in pain intensity ratings to thermal noxious stimuli with females reporting higher intensity than males (al'Absi et al., 2002; Lowery et al., 2003; Kim et al., 2004). However, studies reporting sex differences to cold thermal pain remain equivocal with several studies reporting sex differences (Myers et al., 2001; Lowery et al., 2003; Edwards et al., 2004; Keogh et al., 2005) and others reporting no difference (Keogh et al., 2000; Jones et al., 2003; Pud et al., 2006). To date, studies examining pain following sleep deprivation have focused on pain threshold as the primary outcome variable with all reporting a decrease in threshold following sleep deprivation (Cooperman et al., 1934; Moldofsky \& Scarisbrick, 1976; Onen et al., 2001; Kundermann et al., 2004), yet no between sex comparison has been performed.

Sustained cold noxious stimuli has been demonstrated to produce greater pain ratings that more closely mimic clinical pain conditions than pain threshold analysis (Rainville et al., 1992). Therefore we relied upon the cold pressor test to examine pain intensity following 24-hour total sleep deprivation (TSD). Given the evidence supporting a decrease in pain threshold following sleep deprivation, and data indicating sex differences to cold noxious stimuli, the purpose of this study was to determine the effects of TSD on thermal pain perception. We hypothesized that TSD would augment pain perception during a 2-minute cold pressor test, and females would report higher pain intensity than males. 


\subsection{Methods}

\subsubsection{Subjects}

Thirty healthy subjects (15 men and 15 women) enrolled in the study. All subjects reported to be nonsmokers with no history of cardiovascular disease, autonomic dysfunction, asthma, or diabetes. All female subjects were free of oral contraceptive use, reported regular menstrual cycles (range 26-30 days), and were tested during the early follicular phase of the menstrual cycle. One female subject was excluded from the study when hormone data indicated she was not in the early follicular phase for one testing session. All subjects were screened for obstructive sleep apnea by a board certified sleep physician (J. DellaValla) using the at home ApneaLink (Resmed, San Diego, CA). Exclusion from the study occurred when the apnea-hypopnea index was $\geq 10$ arbitrary units and one male subject was excluded on this basis. Additionally, one female subject was excluded due to failure to complete the testing session resulting in a total sample size of 27 (14 men and 13 women). All subjects participated in an orientation session before providing written informed consent. This study was approved by the Michigan Technological University Institutional Review Board.

\subsubsection{Experimental Design}

Two testing sessions were performed, one following a normal night of sleep at (NS), and one following 24-hour total sleep deprivation. Subjects were tested approximately one month apart to allow for females to be tested during the early follicular phase of the menstrual cycle. Trial order (NS vs. TSD) was randomized to obtain a balanced crossover design. Sleep time for 3 days preceding the study was monitored with wrist actigraphy (Actiwatch 64 Respironics Inc, Bend OR) to ensure subjects were getting adequate sleep.

The day prior to the TSD trial subjects were contacted at 7:00 a.m. and instructed to refrain from napping during the day. They reported to the laboratory at 11 p.m. where two assistants ensured they did not sleep during the night. Subjects refrained from caffeine, alcohol and exercise for 12 hours, and fasted for 8 hours prior to testing. 


\subsubsection{Protocol}

Testing proceeded in both conditions starting at 7:00 a.m. with 3 consecutive recordings of resting blood pressure $(\sim 1$ minute apart) with an automated sphygmomanometer (Omron HEM-907XL, Omron Health Care) following 5 minutes of seated rest. Following a standard breakfast, subjects assumed a supine position on the testing table for instrumentation. Micronreurography was performed to obtain pulse synchronous bursts of muscle sympathetic nerve activity (MSNA). Heart rate was measured continuously with a 3-lead electrocardiogram. Continuous beat-to-beat blood pressure was measured using a Finometer (Finapres Medical Systems, Amsterdam, The Netherlands). Three consecutive recordings of supine blood pressure were recorded immediately preceding the baseline to calibrate the Finometer. Blood pressure was expressed as systolic arterial pressure (SAP), diastolic arterial pressure (DAP), and mean arterial pressure (MAP).

Following instrumentation, subjects lay quietly for an initial 10-minute baseline followed by 3 valsalva maneuvers separated by a one-minute recovery. Subjects were instrumented with venous occlusion plethysmography and a new 5-minute baseline was obtained followed by 5 minutes of mental arithmetic and a 10-minute recovery. This thesis focuses on the third and final intervention, the cold pressor test. A 3-minute baseline was recorded followed by a 2-minute cold pressor test. Briefly the subject's hand was immersed up to the wrist in ice water $\left(\sim 1^{\circ} \mathrm{C}\right)$. Ratings of perceived pain were recorded every 15 seconds by having the subject declare a pain level from a modified Borg scale situated in their field of view. A final 3-minute recovery period was recorded following the cold pressor test. 


\subsubsection{Statistical Analysis}

All statistical analyses were performed using commercial software (SPSS 20.0, SPSS, Chicago, IL). We used repeated-measures ANOVA with condition (NS vs. TSD) as the within-subjects factor and sex (men vs. women) as the between-subjects factor. Post-hoc analysis with paired t-tests was done when significant condition by sex interactions in baseline data, and significant condition by time interactions for the cold pressor test were observed. Results are expressed as mean \pm SE. Significant differences were noted at $\mathrm{p}<0.05$. 


\subsection{Results}

\subsubsection{Baseline Responses}

Table 2.1 displays subject characteristics and mean values for resting blood pressure following both NS and TSD conditions. Blood pressure, expressed as SAP, DAP and MAP, were elevated following TSD in both men and women (condition, $\mathrm{P}<0.01$ ). Baseline hemodynamic data has been reported and discussed (Carter et al., 2012). Sleep time for the three nights preceding the study was not different between NS $(7.3 \pm 0.2 \mathrm{~h}$ in men and 7.6 $\pm 0.2 \mathrm{~h}$ in women) and TSD $(7.6 \pm 0.3 \mathrm{~h}$ in men and $7.5 \pm 0.3$ $\mathrm{h}$ in women) conditions.

Table 2.1. Baseline values for men and women following normal sleep and 24-hour total sleep deprivation.

\begin{tabular}{|c|c|c|c|c|c|c|c|}
\hline \multirow[b]{2}{*}{ Variable } & \multicolumn{2}{|c|}{ Men } & \multicolumn{2}{|c|}{ Women } & \multicolumn{3}{|c|}{$P$ Value } \\
\hline & NS & TSD & NS & TSD & $\begin{array}{c}\text { Conditio } \\
n\end{array}$ & Sex & $\begin{array}{c}\text { Condition } \\
\times \text { Sex }\end{array}$ \\
\hline Age, years & $22 \pm 1$ & -- & $22 \pm 1$ & -- & -- & -- & -- \\
\hline Height, cm & $176 \pm 2$ & -- & $165 \pm 2$ & -- & -- & -- & -- \\
\hline Weight, kg & $79 \pm 4$ & $79 \pm 4$ & $63 \pm 3$ & $64 \pm 3$ & $P=0.48$ & $P<0.01$ & $P=0.18$ \\
\hline $\mathrm{SAP}, \mathrm{mmHg}$ & $109 \pm 2$ & $115 \pm 2$ & $97 \pm 2$ & $98 \pm 2$ & $P<0.01$ & $P<0.05$ & $P<0.03$ \\
\hline $\mathrm{DAP}, \mathrm{mmHg}$ & $58 \pm 2$ & $61 \pm 1$ & $56 \pm 1$ & $59 \pm 2$ & $P<0.01$ & $P=0.36$ & $P=0.33$ \\
\hline MAP, $\mathrm{mmHg}$ & $75 \pm 1$ & $79 \pm 1$ & $70 \pm 1$ & $72 \pm 1$ & $P<0.01$ & $P<0.01$ & $P=0.24$ \\
\hline $\begin{array}{l}\text { Estradiol, } \\
\mathrm{pg} / \mathrm{ml}\end{array}$ & $24.8 \pm 2.0$ & $20.4 \pm 0.9$ & $36.7 \pm 9.0$ & $29.9 \pm 2.8$ & $P=0.06$ & $P=0.03$ & $P=0.4$ \\
\hline $\begin{array}{l}\text { Progesterone, } \\
\mathrm{ng} / \mathrm{ml}\end{array}$ & $2.15 \pm 0.17$ & $1.80 \pm 0.15$ & $2.11 \pm 0.19$ & $1.33 \pm 0.14$ & $P<0.01$ & $P=0.12$ & $P<0.05$ \\
\hline
\end{tabular}

Values are mean \pm SE. $n=14$ men and $n=13$ unless otherwise noted; NS, normal sleep; TSD, total sleep deprivation; SAP, systolic arterial blood pressure; DAP, diastolic arterial blood pressure; MAP, mean arterial blood pressure. Estradiol and Progesterone, $n=26$ (14 men and 12 women). 


\subsubsection{Pain Responses}

Figure 2.1 demonstrates that pain intensity increased during CPT following both NS and TSD conditions (time, $\mathrm{p}<0.05$ ), and that pain intensity was augmented following TSD when compared to NS $(\Delta 1.23$ a.u. time $\mathrm{x}$ condition, $\mathrm{p}<0.05)$. The augmented pain response to CPT following TSD was noted when pain intensity was expressed as mean (NS $6.95 \pm 0.5$ vs. TSD $8.18 \pm 0.5$, condition, $\mathrm{p}<0.01$ ) or peak pain intensity (NS $8.91 \pm 0.6$ vs. TSD $10.22 \pm 0.5$, condition, $\mathrm{p}<0.01$ ) as displayed in Figure 2.2. Figure 2.3 demonstrates that there was no sex differences in the pain intensity during CPT in either NS or TSD sleep condition (condition $x$ time $x$ sex, $p>0.05$ ). There was no correlation between changes in pain intensity and sex hormone levels following TSD.

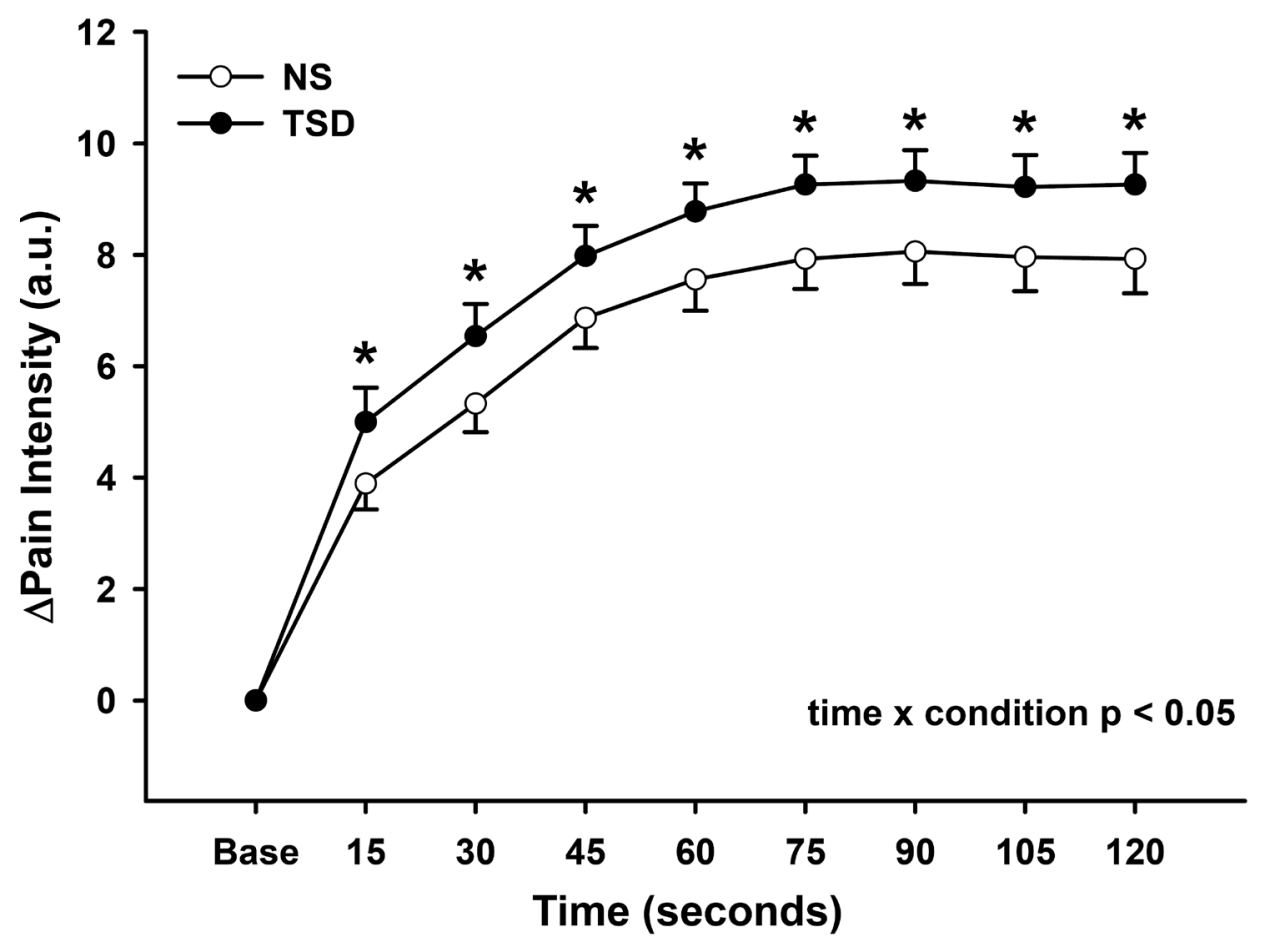

Figure 2.1. Changes in pain intensity during 2-minute cold pressor test following normal sleep (NS) and 24-hour total sleep deprivation (TSD). TSD augmented ( $\sim \Delta 1.2$ a.u.) the pain intensity response to CPT. ${ }^{*} \mathrm{p}<0.05 \mathrm{NS}$ vs TSD. 

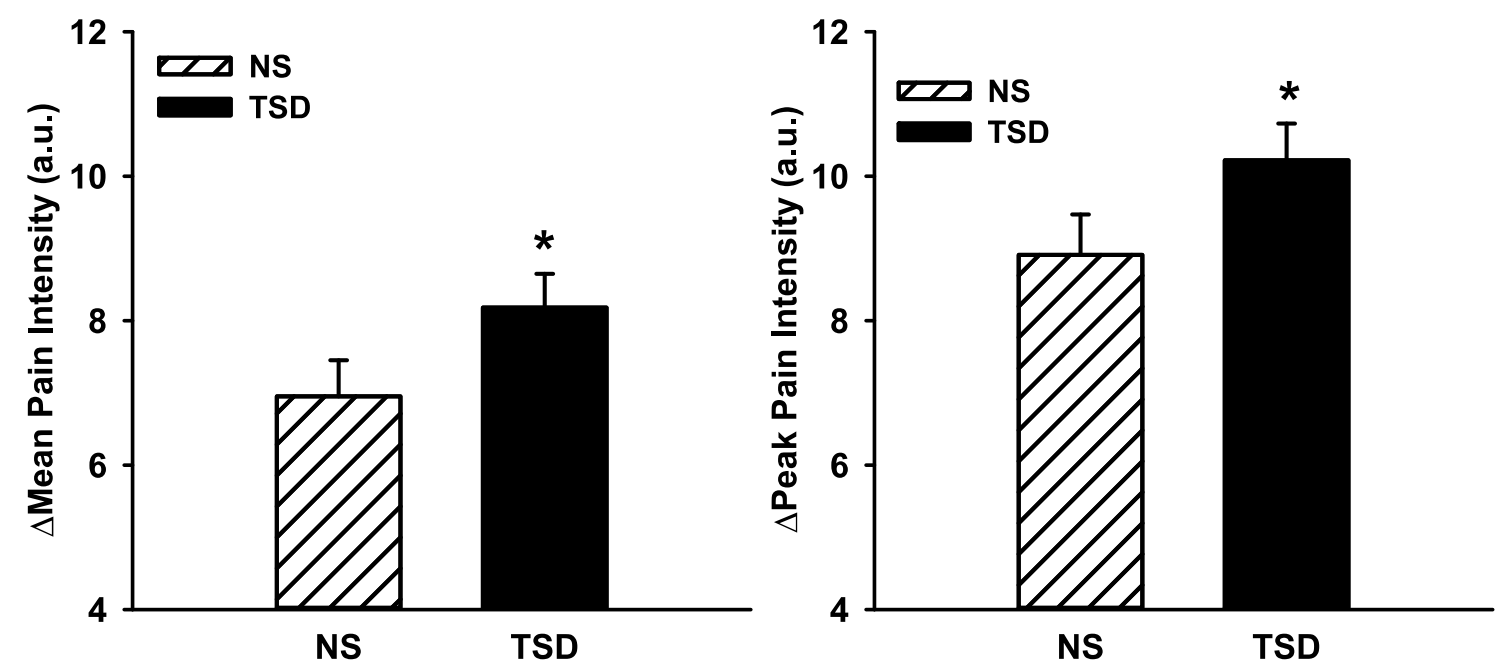

Figure 2.2 Changes in mean and peak pain intensity during 2-minute cold pressor test (CPT) following normal sleep (NS) and (TSD). TSD elevated the mean and peak pain response to CPT. ${ }^{*} \mathrm{p}<0.05 \mathrm{NS}$ vs TSD.

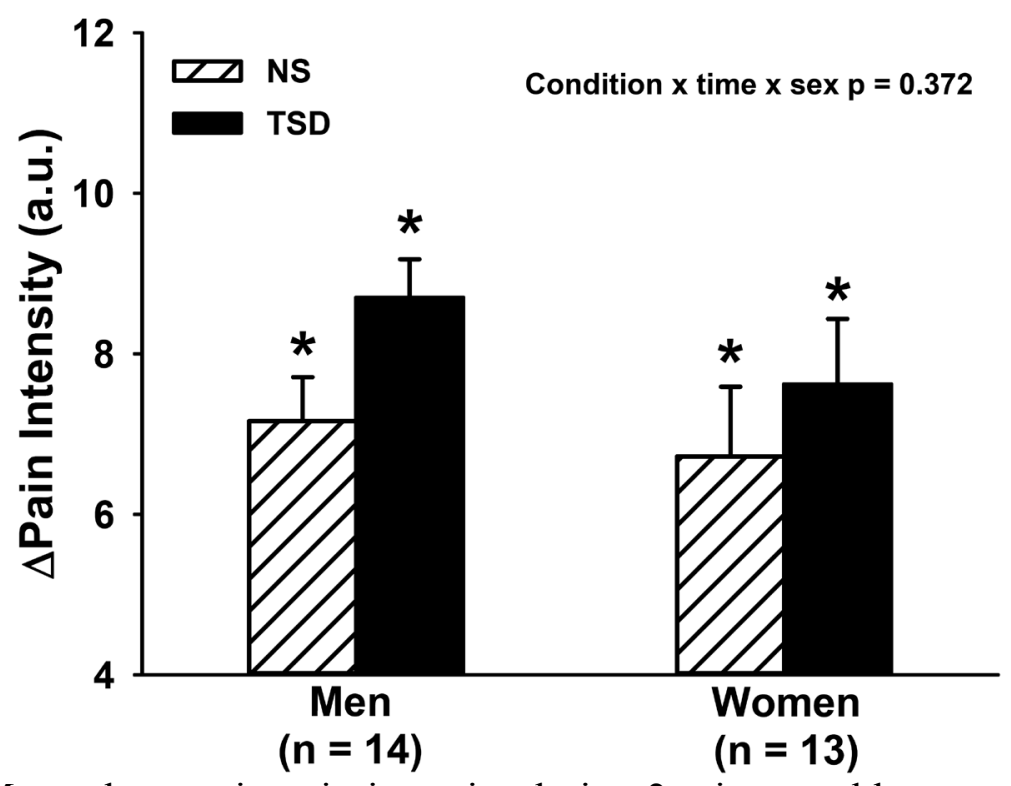

Figure 2.3. Mean changes in pain intensity during 2-minute cold pressor test (CPT) in men and women. There were no sex differences in the pain intensity responses during CPT following normal sleep (NS) and total sleep deprivation (TSD). ${ }^{*} p<0.05$ CPT vs. baseline. 


\subsection{Discussion}

The current study examined the influence of 24-hour TSD on pain intensity during CPT, and we report two novel findings. First, TSD augmented pain intensity responses during CPT. Second, contrary to our hypothesis, there were no sex differences in the pain intensity response to CPT. The use of a sustained stimulus to elicit pain provides a closer approximation to clinical pain than other measure such as threshold analysis.

Previous studies suggest that sleep deprivation or sleep loss results in an augmented pain response in healthy subjects (Cooperman et al., 1934; Onen et al., 2001; Kundermann et al., 2004; Roehrs et al., 2006; Azevedo et al., 2011). Hyperalgesia has also been demonstrated following sleep loss in patients suffering from fibromyalgia (Moldofsky et al., 1975; Lentz et al., 1999) although not all studies support this finding (Older et al., 1998). The testing paradigms demonstrating hyperalgesia following sleep loss indicate an increased sensitivity to mechanical and heat stimuli, however, only one study included noxious cold stimuli following sleep loss and reported a trend towards an augmented pain response when examining pain threshold (Kundermann et al., 2004). The current study demonstrates that 24-hour TSD augments the pain intensity response to sustained noxious cold thermal stimuli.

It is well established that sleep loss augments mechanical pain perception in humans (Cooperman et al., 1934; Onen et al., 2001), but the effects on thermal pain are less clear, and little attention has been paid to cold stimuli. Kundermann et al. (2004) examined heat and cold pain threshold utilizing a protocol with two TSD nights separated by two recovery nights. They reported a decrease in heat pain threshold following TSD and a trend for a decrease in cold pain threshold. Further studies examining noxious heat stimuli have since supported the notion that sleep loss augments the heat pain response in humans (Roehrs et al., 2006; Azevedo et al., 2011). Kundermann et al. (2004) only reported a trend towards a decrease in cold pain threshold following sleep deprivation, whereas the current study demonstrated a significant increase in pain intensity during noxious cold stimuli. 
The variability in pain results following sleep deprivation may be due to stimulus modality. The augmented mechanical and heat pain response following sleep deprivation is well established through studies examining pain threshold analysis. Mechanical and heat nociceptors primarily fall in the A-delta category and are involved in the fast pain response making them ideally suited for threshold analysis. However, cold pain is primarily carried by slow C-fibers, making it less suitable for threshold analysis. Whereas Kundermann et al. (2004) only noted a trend towards a decrease in cold pain threshold involving a brief stimulus, the current study demonstrated a robust augmentation in pain intensity to sustained cold stimuli following TSD. The difference between the current study and Kundermann et al. (2004) may be due to the stimulus modality. We believe that a sustained stimulus provides a more accurate representation of the perception of cold pain than threshold analysis. Furthermore, sustained painful stimuli may provide a closer approximation to clinical pain than threshold analysis (Rainville et al., 1992).

Evidence suggests that the pain response to noxious stimuli varies between the sexes, and that women generally report more pain than men. Contrary to our hypothesis, the current study demonstrated no sex differences in pain intensity during CPT following either sleep condition. While the many studies report sex differences to noxious cold stimuli (Myers et al., 2001; Lowery et al., 2003; Sarlani et al., 2003; Edwards et al., 2004; Keogh et al., 2005; Nielsen et al., 2008), the data are variable and studies also report no sex differences (Keogh et al., 2000; Jones et al., 2003; Tousignant-Laflamme et al., 2005; Pud et al., 2006). The current study suggests that the factors mediating a differential pain response between the sexes are not significantly influence by TSD.

Kundermann et al. (2004) examined thermal sensitivity to determine if a change in overall somatosensory sensitivity was responsible for hyperalgesia following TSD. Their results indicate that thermal sensitivity was not altered by TSD and therefore, the changes in pain threshold were due to mechanisms other than a change in overall, general somatosensory sensitivity. The question then arises as to what is responsible for the change in pain perception after sleep loss. Studies in animals suggest a possible impairment in the endogenous opioid system (Ukponmwan et al., 1984; Fadda et al., 
1991) contributing to an augmented pain response. Furthermore, Smith et al. (2007) used a diffuse noxious inhibitory control (DNIC) protocol following partial sleep deprivation and demonstrated a reduction in pain inhibitory capacity. These results suggest an alteration in pain inhibition following sleep deprivation that is often attributed to endogenous opioids. A recent study examining pain and sleep deprivation in humans also demonstrated an increase in prostaglandins following sleep deprivation (Haack et al., 2009). The prostaglandin system is a mediator in the inflammatory response including inflammation-mediated pain symptoms. Haack et al. (2009) attributed the elevated pain response to an increase in prostaglandins and described both peripheral and central actions of the prostaglandin system that potentially mediate hyperalgesia following sleep deprivation. The mechanisms responsible for hyperalgesia following sleep loss require more attention with a greater emphasis on data from human subjects.

In summary, 24-hour TSD increased pain intensity responses during CPT. The augmented pain response to sustained noxious cold stimuli following TSD extends the findings provided by pain threshold analysis in that extended exposure to painful stimuli provides a closer association to clinical pain (Rainville et al., 1992). Sustained painful stimuli are usually present in chronic painful disease conditions, and the results of this study indicate that measures should be taken to ensure these patients receive adequate sleep. 


\section{Chapter 3 Study 2}

\subsection{Introduction}

Studies indicate that $30 \%$ of the population may suffer from insomnia (Health, 2005; Roth, 2007), and evidence suggests it's more prevalent in women compared to men (Soares, 2005; Sivertsen et al., 2009). Subjective sleep quality and alertness are decreased during the ML phase of the menstrual cycle (Manber \& Bootzin, 1997; Shechter et al., 2010) indicating a potential contributing factor to the increased prevalence of insomnia in women. Reports suggest that sleep loss leads to hyperalgesia (Kundermann et al., 2004; Roehrs et al., 2006) and pain intensity is increased in the Luteal phase of the menstrual cycle (Hapidou \& De Catanzaro, 1988; Stening et al., 2007) demonstrating a possible link between menstrual phase and an increased risk for insomnia in women. Therefore, the purpose of this study was to determine the effects of TSD on thermal pain perception during the early follicular and mid luteal phases of the menstrual cycle in women. We hypothesized that pain perception during a 2minute cold pressor test would be augmented in the mid luteal phase of the menstrual cycle.

\subsection{Methods}

\subsubsection{Subjects}

Ten healthy women were enrolled in the study. All subjects reported to be nonsmokers with no history of cardiovascular disease, autonomic dysfunction, asthma, or diabetes. Female subjects were free of oral contraceptive use, and reported regular menstrual cycles (range 26-30 days). All subjects participated in an orientation session before providing written informed consent. This study was approved by the Michigan Technological University Institutional Review Board. 


\subsubsection{Experimental Design}

Two testing sessions were performed, both following 24-hour total sleep deprivation (TSD) in the lab. Subjects were tested once during the early follicular phase of the menstrual cycle (2-5 days following onset of menstruation), and once during the mid-luteal phase of the menstrual cycle (8-10 days following the LH surge). Trial order (EF vs. ML) was randomized to obtain a balanced crossover design. Sleep time for 3 days preceding the study was monitored with wrist actigraphy (Actiwatch 64 Respironics Inc, Bend OR) to ensure subjects were getting adequate sleep.

The day prior to each testing session subjects were contacted at 7:00 a.m. to ensure they were awake and instructed to refrain from napping during the day. They reported to the laboratory at 11 p.m. where two assistants ensured they did not sleep during the night. Subjects refrained from caffeine, alcohol and exercise for 12 hours, and fasted for 8 hours prior to testing.

\subsubsection{Protocol}

Testing proceeded in both conditions starting at 7:00 a.m. with 3 consecutive recordings of resting blood pressure $(\sim 1$ minute apart) with an automated sphygmomanometer (Omron HEM-907XL, Omron Health Care) following 5 minutes of seated rest. Following a standard breakfast, subjects assumed a supine position on the testing table for instrumentation. Microneurography was performed to obtain pulse synchronous bursts of MSNA. Heart rate was measured continuously with a 3-lead electrocardiogram. Continuous beat-to-beat blood pressure was measured using a Finometer (Finapres Medical Systems, Amsterdam, The Netherlands). Three consecutive recordings of supine blood pressure were recorded immediately preceding the baseline to calibrate the Finometer. Blood pressure was expressed as systolic arterial pressure (SAP), diastolic arterial pressure (DAP), and mean arterial pressure (MAP).

Following instrumentation, subjects lay quietly for an initial 10-minute baseline. Subjects were then instrumented for venous occlusion plethysmography and a new 5minute baseline was obtained followed by 5 minutes of mental arithmetic and a 10minute recovery. This thesis focuses on the third and final intervention, the cold pressor 
test. A 3-minute baseline was recorded followed by a 2-minute cold pressor test. Briefly the subject's hand was immersed up to the wrist in ice water $\left(\sim 1^{\circ} \mathrm{C}\right)$. Ratings of perceived pain were recorded every 15 seconds by having the subject declare a pain level from a modified Borg scale situated in their field of view. A final 3-minute recovery period was recorded following the cold pressor test.

\subsubsection{Statistical Analysis}

All statistical analyses were performed using commercial software (SPSS 20.0, SPSS, Chicago, IL). Baseline variables were compared using paired t-tests. We used repeatedmeasures ANOVA with condition (EF vs. ML) as the within-subjects factor for comparisons during the cold pressor test. Results are expressed as mean \pm SE. Significant differences were noted at $\mathrm{p}<0.05$. 


\subsection{Results}

\subsubsection{Baseline Responses}

Table 3.1 demonstrates seated resting blood pressure recordings and female gonadal hormone concentrations. Subject weight and body mass index (BMI) was unchanged between the two testing sessions and resting blood pressure was not different between the two phases of the menstrual cycle. Importantly, estradiol and progesterone concentrations were significantly higher during the ML phase of the menstrual cycle. Finally, sleep time for the three nights preceding the study was not different between the $\mathrm{EF}(7.3 \pm 0.3 \mathrm{~h})$ and $\mathrm{ML}(7.2 \pm 0.2 \mathrm{~h})$ phases.

Table 3.1. Resting variables for early follicular and mid-luteal testing sessions.

\begin{tabular}{lcc} 
Variable & EF & ML \\
\hline Age (years) & $21 \pm 1$ & -- \\
Height $(\mathrm{cm})$ & $166 \pm 2$ & - \\
Weight $(\mathrm{kg})$ & $71 \pm 16$ & $71 \pm 16$ \\
BMI $\left(\mathrm{kg} / \mathrm{m}^{2}\right)$ & $26 \pm 2$ & $26 \pm 2$ \\
SAP $(\mathrm{mmHg})$ & $105 \pm 5$ & $107 \pm 5$ \\
DAP $(\mathrm{mmHg})$ & $69 \pm 4$ & $65 \pm 4$ \\
MAP $(\mathrm{mmHg})$ & $81 \pm 4$ & $79 \pm 4$ \\
HR $(\mathrm{mmHg})$ & $62 \pm 3$ & $62 \pm 2$ \\
Estradiol $(\mathrm{pg} / \mathrm{ml})$ & $28.6 \pm 2.9$ & $65.7 \pm 9.9^{*}$ \\
Progesterone $(\mathrm{ng} / \mathrm{ml})$ & $1.47 \pm 0.21$ & $4.9 \pm 1.05^{*}$ \\
\hline
\end{tabular}

Values are mean $\pm \mathrm{SE}$; $\mathrm{n}=10$; EF, Early Follicular; ML, Mid-Luteal; BMI, body mass index; SAP, systolic arterial pressure; DAP, diastolic arterial pressure; MAP, mean arterial pressure; HR heart rate; * $\mathrm{P}<0.05$, EF vs. ML. 


\subsubsection{Pain Responses}

Figure 3.1 demonstrates that pain intensity increases during CPT in both the EF and ML phase of the menstrual cycle (time, $\mathrm{p}<0.05$ ) however there was no difference in pain intensity ratings between the two cycles (time $x$ condition, $p=0.48$ ). Similarly, figure 3.2 displays that there were differences in the mean or peak pain response between the EF and ML phase of the menstrual cycle. There was no correlation between pain intensity and sex hormone levels following either condition.

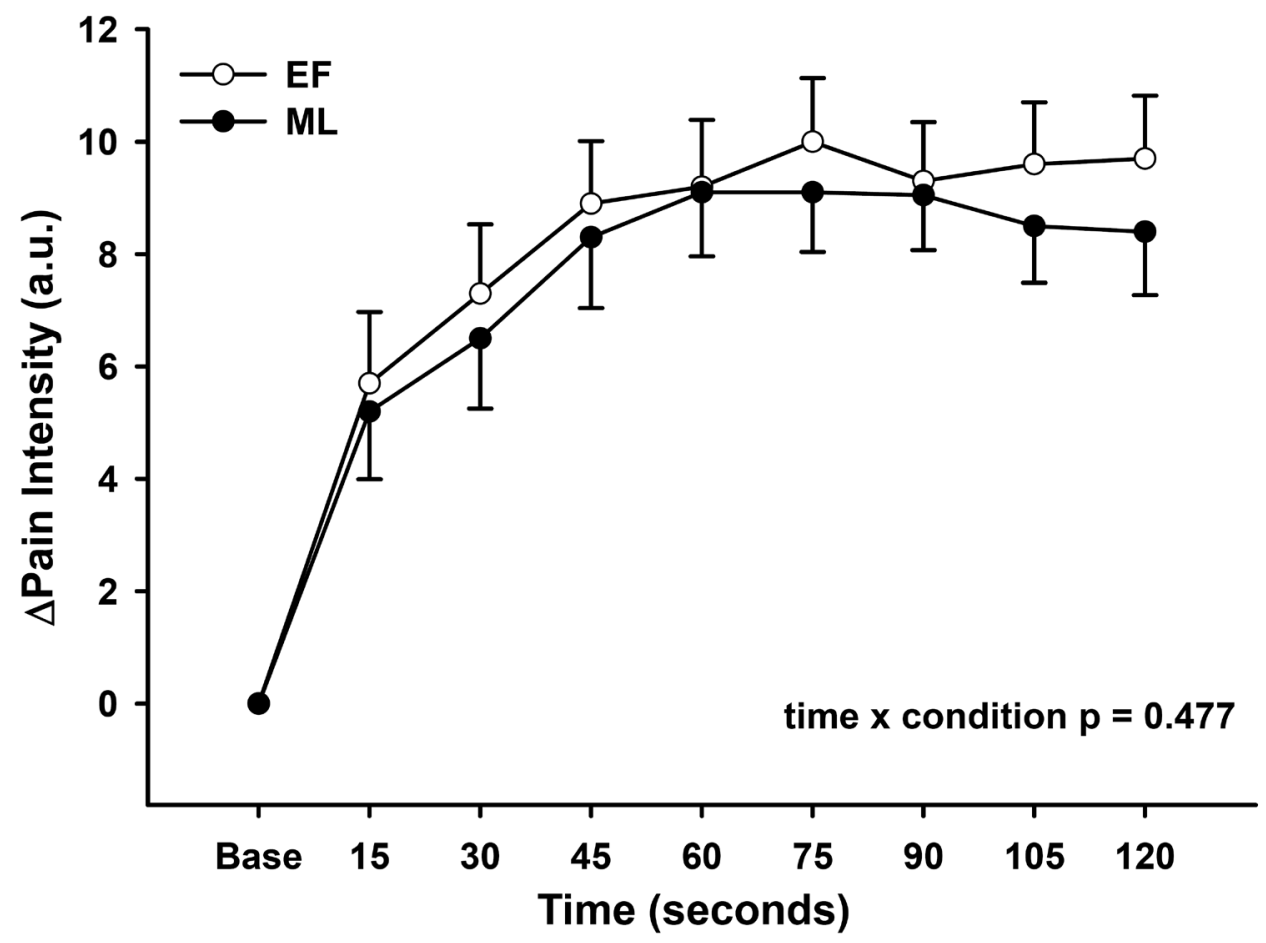

Figure 3.1. Changes in pain intensity during 2-minute cold pressor test during EF and ML phases of the menstrual cycle following 24-hour total sleep deprivation (TSD). Pain intensity was not different between the two phases of the menstrual cycle following TSD. 

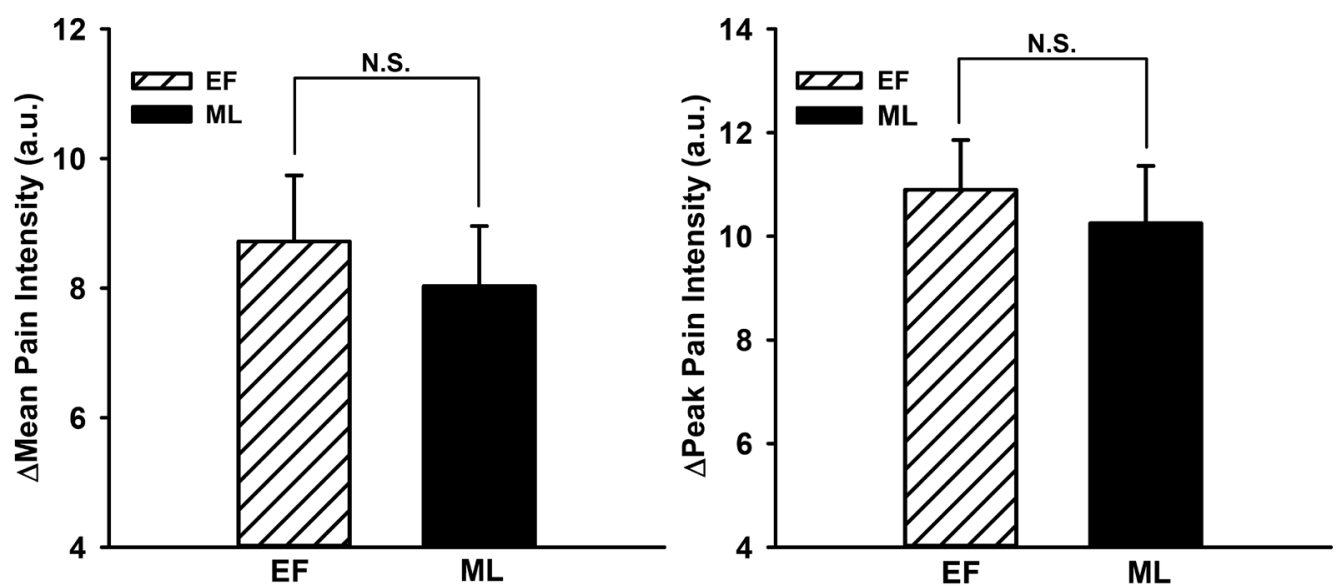

Figure 3.2. Changes in mean and peak pain intensity during 2-minute cold pressor test (CPT) during EF and ML phases of the menstrual cycle following 24-hour total sleep deprivation (TSD). Menstrual phase did not alter the average pain intensity or peak pain intensity following TSD.

\subsection{Discussion}

The current study examined the influence of thermal pain perception following TSD during two phases of the menstrual cycle. Contrary to out hypothesis, the results or our study indicate that pain intensity during the cold pressor test after TSD is not different between the EF and ML phases of the menstrual cycle. Our findings suggest that collectively, TSD and menstrual phase do result in a differential pain response between the EF and ML phase of the menstrual cycle.

To date, studies have not examined the combined effect of sleep deprivation and menstrual phase on experimentally induced pain. Evidence indicates that sleep loss alone augments perceived pain responses (Onen et al., 2001; Kundermann et al., 2004; Roehrs et al., 2006; Smith et al., 2007), and several studies have demonstrated that pain sensitivity may be elevated in the luteal phase of the menstrual cycle (Kuczmierczyk \& Adams, 1986; Hapidou \& De Catanzaro, 1988; Fillingim et al., 1997; Pfleeger et al., 1997; Stening et al., 2007). They attribute this response to elevated gonadal hormone levels, particularly progesterone. Despite the independent effects of TSD and menstrual phase on perceived pain, the current study did not demonstrate any difference in pain intensity between the EF and ML phases of the menstrual cycle following TSD. This 
study provides an indication that collectively TSD and elevated gonadal hormone levels do not result in a differential pain response between menstrual phases.

Women are more sensitive to pain compared to men (Myers et al., 2001; Lowery et al., 2003; Klatzkin et al., 2010) and one potential mediator of these differences in the variability of sex hormone levels during the menstrual cycle in females. Studies examining pain across menstrual phase have demonstrated conflicting results. Results from animal studies demonstrate an altered pain response with fluctuations in gonadal hormone levels and most demonstrate elevated pain sensitivity during high hormone phases (Molina et al., 1990; Frye et al., 1993; Martinez-Gomez et al., 1994; Kayser et al., 1996). Contrary to results from animal studies, human experiments examining experimentally induced pain from heat, ischemia, and pressure across the menstrual cycle have not demonstrated consistent results (Amodei \& Nelson-Gray, 1989; Fillingim et al., 1997; Pfleeger et al., 1997; Granot et al., 2001; Straneva et al., 2002; Sherman et al., 2005; Klatzkin et al., 2010) although studies that do report a difference, demonstrate enhance pain sensitivity during high hormone phases. Variability in the stimulus modality, experimental procedure, or definition of menstrual phase may account for the conflicting results.

Several recent studies have examined pain induced by the cold pressor test across menstrual phase. Klatzkin et al. (2010) and Kowalczyk et al. (2006) demonstrated no difference in pain threshold or tolerance during the cold pressor between the EF and ML phase in a large sample of women, however, these studies differ from the current study in that they did not include a TSD protocol. Stening et al. (2007) measured pain tolerance, pain activation time, and maximal pain during the cold pressor test across the menstrual cycle. The only positive finding they reported was that pain activation time (AT), the amount of time it takes for pain to reach moderate levels, was decreased in the late luteal phase of the menstrual cycle. They further demonstrated that the decrease in AT was more pronounced in periods where progesterone was rising while estradiol remained constant and when estradiol concentrations were rising the diminished AT response to progesterone was decreased. Estradiol and progesterone levels were both substantially elevated in our study, however, there was no correlation between ratings of pain intensity 
and hormone levels. Similar to our study, Stening et al. (2007) reported no difference in pain intensity rated from a visual analog scale across the menstrual cycle. Furthermore, while AT may be used as an index of pain threshold, the method utilized to determine AT has not been prevalent in similar study designs.

Sleep deprivation and sleep loss result in heightened pain sensitivity (Kundermann et al., 2004; Roehrs et al., 2006), yet more studies are needed to understand the contributing mechanisms. Studies in animals (Ukponmwan et al., 1984; Fadda et al., 1991) and humans (Smith et al., 2007) point to an inhibition of the endogenous opioid system following sleep deprivation. Smith et al. (2006) demonstrated that high levels of estrogen were associated with elevated activation of endogenous opioid neurotransmission, whereas low levels of estrogen resulted in an attenuation of endogenous opioids in females. They also demonstrated a correlation between endogenous opioid activity and pain perception. These results suggest that perhaps the variability of estrogen may have a strong influence on perceived pain. In the current study we demonstrated an increase in estrogen and progesterone in the ML phase of the menstrual cycle, but the increase was less than several similar studies (Kowalczyk et al., 2006; Stening et al., 2007; Klatzkin et al., 2010). This may provide an explanation as to why we failed to see a difference in pain intensity between the two phases. In Study 1 presented in chapter 2, estradiol demonstrated a modest by not statistically significant decrease following TSD whereas we observed that progesterone levels were decreased following TSD. This provides a possible explanation for the blunted hormone levels during the ML phase of the current study. Therefore, the combined effect of sleep deprivation and menstrual phase may not have induced any collective effect.

In conclusion, we demonstrated that there was no difference in the pain intensity response to the cold pressor test between the EF and ML phases of the menstrual cycle following TSD. Independently, sleep loss and menstrual phase may alter pain sensitivity, but collectively, they do not result in a differential pain response. 


\section{Chapter 4 Summary, Limitations, and Future Directions}

\subsection{Summary}

Sleep loss and pain have a bi-directional relationship whereby loss of sleep augments pain and pain contributes to sleep loss. This relationship has dire consequences for patients suffering from chronic pain. In Study 1 we demonstrated an augmented pain response to sustained painful stimuli following TSD, however, we did not observe any sex differences. This is the first study to examine TSD induced pain during sustained noxious stimulation. Protocols relying on sustained noxious stimuli provide a closer approximation to clinical pain that threshold analysis (Rainville et al., 1992). Therefore, TSD augments pain intensity during CPT, however, contrary to our secondary hypothesis, there were no sex differences.

There is higher prevalence of insomnia in women and one potential mediator is gonadal sex hormones. In Study 2 we demonstrated that the combined effect of TSD and elevated gonadal hormones did not result in a differential pain response between the EF and ML phases of the menstrual cycle. While these findings were contrary to our hypothesis, this is the first study to examine the collective effects of TSD and menstrual phase on pain intensity.

\subsection{Limitations and Future Work}

One potential limitation is that we only measure pain evoked by one type of stimulus. Future studies involving sleep deprivation and pain should involve the assessment of more than one type of stimuli since pain responses can vary depending on the stimulus modality due to the numerous types of nociceptors. Post-exercise muscle ischemia is another method for assessing sustained pain in human subjects and could be included in future protocols. Another potential limitation is that we did not have a comparison for sleep deprivation during the ML phase of the menstrual cycle. While estradiol and progesterone levels were elevated during the ML phase, they did not reach levels comparable to similar studies following normal sleep. Study 1 gives us an 
indication that progesterone levels may be decreased following TSD and the ability to determine the effects of TSD during the ML phase could be beneficial.

Study 2 was the first to examine the collective effects of TSD and menstrual phase on pain intensity. The interactions between sleep and hormones are complex, and future work should include a DNIC protocol to investigate the effects of hormones and sleep deprivation the endogenous opioid system. Finally, while sleep deprivation provides a model to assess the effects of sleep loss, sleep restriction may provide a closer approximation to sleep loss in healthy subjects, and disease states. Future studies involving sleep loss and pain should include a sleep restriction protocol. 


\section{References}

Achermann P. (2004). The two-process model of sleep regulation revisited. Aviat Space Environ Med 75, A37-43.

al'Absi M, Petersen KL \& Wittmers LE. (2002). Adrenocortical and hemodynamic predictors of pain perception in men and women. Pain 96, 197-204.

Amodei N \& Nelson-Gray RO. (1989). Reactions of dysmenorrheic and nondysmenorrheic women to experimentally induced pain throughout the menstrual cycle. J Behav Med 12, 373-385.

Apkarian AV, Bushnell MC, Treede RD \& Zubieta JK. (2005). Human brain mechanisms of pain perception and regulation in health and disease. Eur J Pain 9, 463-484.

Aserinsky E \& Kleitman N. (1953). Regularly occurring periods of eye motility, and concomitant phenomena, during sleep. Science 118, 273-274.

Atkinson J, Ancoli-Israel S, Slater MA, Garfin SR \& Gillin C. (1988). Subjective sleep disturbance in chronic back pain. Clin J Pain 4, 225.

Ayesh EE, Jensen TS \& Svensson P. (2007). Somatosensory function following painful repetitive electrical stimulation of the human temporomandibular joint and skin. Exp Brain Res 179, 415-425.

Azevedo E, Manzano GM, Silva A, Martins R, Andersen ML \& Tufik S. (2011). The effects of total and REM sleep deprivation on laser-evoked potential threshold and pain perception. Pain 152, 2052-2058.

Baker FC, Waner JI, Vieira EF, Taylor SR, Driver HS \& Mitchell D. (2004). Sleep and 24 hour body temperatures: a comparison in young men, naturally cycling women and women taking hormonal contraceptives. J Physiol 530, 565-574.

Basbaum AI, Bautista DM, Scherrer G \& Julius D. (2009). Cellular and molecular mechanisms of pain. Cell 139, 267-284.

Bell SC. (1811). Idea of a New Anatomy of the Brain: Submitted for the Observations of his Friends. Strahan and Preston.

Berger RJ \& Oswald I. (1962). Effects of sleep deprivation on behaviour, subsequent sleep, and dreaming. J Ment Sci 108, 457-465. 
Berson DM, Dunn FA \& Takao M. (2002). Phototransduction by retinal ganglion cells that set the circadian clock. Science 295, 1070-1073.

Bessou P \& Perl ER. (1969). Response of cutaneous sensory units with unmyelinated fibers to noxious stimuli. J Neurophysiol 32, 1025-1043.

Bishop G, Heinbecker P \& O'leary J. (1933). The function of the non-myelinated fibers of the dorsal roots. American Journal of Physiology--Legacy Content 106, 647-669.

Blake H \& Gerard R. (1937). BRAIN POTENTIALS DURING SLEEP. American Journal of Physiology--Legacy Content 119, 692-703.

Borbely AA. (1982). A two process model of sleep regulation. Hum Neurobiol 1, 195204.

Borbely AA, Baumann F, Brandeis D, Strauch I \& Lehmann D. (1981). Sleep deprivation: effect on sleep stages and EEG power density in man. Electroencephalogr Clin Neurophysiol 51, 483-495.

Brennum J, Kjeldsen M, Jensen K \& Jensen TS. (1989). Measurements of human pressure-pain thresholds on fingers and toes. Pain 38, 211-217.

Brown-Sequard C. (1868). Lectures ON THE PHYSIOLOGY AND PATHOLOGY OF THE NERVOUS SYSTEM; AND ON THE TREATMENT OF ORGANIC NERVOUS AFFECTIONS. The Lancet 92, 593-596.

Buchanan HM \& Midgley JA. (1987). Evaluation of pain threshold using a simple pressure algometer. Clin Rheumatol 6, 510-517.

Burgess PR \& Perl ER. (1967). Myelinated afferent fibres responding specifically to noxious stimulation of the skin.J Physiol 190, 541-562.

Cagnacci A, Elliott J \& Yen S. (1992). Melatonin: a major regulator of the circadian rhythm of core temperature in humans. Journal of Clinical Endocrinology \& Metabolism 75, 447-452.

Cagnacci A, Soldani R, Laughlin GA \& Yen S. (1996). Modification of circadian body temperature rhythm during the luteal menstrual phase: role of melatonin. $J$ Appl Physiol 80, 25-29.

Cannon WB. (1939). The wisdom of the body. W.W. Norton \& Company, New York,.

Carskadon MA \& Dement WC. (1981). Cumulative effects of sleep restriction on daytime sleepiness. Psychophysiology 18, 107-113. 
Carskadon MA \& Dement WC. (1994). Normal human sleep: an overview. Principles and practice of sleep medicine 4, 13-23.

Carter JR, Durocher JJ, Larson RA, DellaValla JP \& Yang H. (2012). Sympathetic neural responses to 24-hour sleep deprivation in humans: sex differences. Am J Physiol Heart Circ Physiol 302, H1991-1997.

Clayton R. (1989). Gonadotrophin-releasing hormone: its actions and receptors. Journal of endocrinology 120, 11-19.

Cooperman N, Mullin F \& Kleitman N. (1934). Studies on the physiology of sleep: XI. Further observations on the effects of prolonged sleeplessness. American Journal of Physiology--Legacy Content 107, 589-593.

Crook J, Rideout E \& Browne G. (1984). The prevalence of pain complaints in a general population. Pain 18, 299-314.

Daan S, Beersma DG \& Borbely AA. (1984). Timing of human sleep: recovery process gated by a circadian pacemaker. Am J Physiol 246, R161-183.

Dallenbach KM. (1939). Pain: history and present status. Am J Psychol 52, 331-347.

Dement W \& Kleitman N. (1957). Cyclic variations in EEG during sleep and their relation to eye movements, body motility, and dreaming. Electroencephalogr Clin Neurophysiol 9, 673-690.

Driver H, Dijk D, Werth E, Biedermann K \& Borbely A. (1996). Sleep and the sleep electroencephalogram across the menstrual cycle in young healthy women. Journal of Clinical Endocrinology \& Metabolism 81, 728-735.

Edwards RR, Haythornthwaite JA, Sullivan MJ \& Fillingim RB. (2004). Catastrophizing as a mediator of sex differences in pain: differential effects for daily pain versus laboratory-induced pain. Pain 111, 335-341.

Erlanger J \& Gasser H. (1922). A Study of the Action Currents of Nerve with the Cathode Ray Oscillograph. Amer J Physiol 62, 496-495.

Erlanger J \& Gasser HS. (1924). The compound nature of the action current of nerve as disclosed by the cathode ray oscillograph. American Journal of Physiology-Legacy Content 70, 624-666.

Fadda P, Tortorella A \& Fratta W. (1991). Sleep deprivation decreases mu and delta opioid receptor binding in the rat limbic system. Neurosci Lett 129, 315-317. 
Feinberg I, Fein G \& Floyd TC. (1980). EEG patterns during and following extended sleep in young adults. Electroencephalogr Clin Neurophysiol 50, 467-476.

Fillingim RB, King CD, Ribeiro-Dasilva MC, Rahim-Williams B \& Riley JL, 3rd. (2009). Sex, gender, and pain: a review of recent clinical and experimental findings. $J$ Pain 10, 447-485.

Fillingim RB, Maixner W, Girdler SS, Light KC, Harris MB, Sheps DS \& Mason GA. (1997). Ischemic but not thermal pain sensitivity varies across the menstrual cycle. Psychosom Med 59, 512-520.

Frye CA, Cuevas CA \& Kanarek RB. (1993). Diet and estrous cycle influence pain sensitivity in rats. Pharmacol Biochem Behav 45, 255-260.

Gaskin DJ \& Richard P. (2012). The Economic Costs of Pain in the United States. J Pain.

Goldenberg RL, Vaitukaitis JL \& Ross GT. (1972). Estrogen and follicle stimulation hormone interactions on follicle growth in rats. Endocrinology 90, 14921498.

Goldscheider A. (1894). Ueber den Schmerz in physiologischer und klinischer Hinsicht. August Hirschwald.

Gowers SWR. (1877). A case of unilateral gunshot injury to the spinal cord.

Granot M, Yarnitsky D, Itskovitz-Eldor J, Granovsky Y, Peer E \& Zimmer EZ. (2001). Pain perception in women with dysmenorrhea. Obstet Gynecol 98, 407-411.

Gulevich G, Dement W \& Johnson L. (1966). Psychiatric and EEG observations on a case of prolonged (264 hours) wakefulness. Arch Gen Psychiatry 15, 29-35.

Haack M, Lee E, Cohen DA \& Mullington JM. (2009). Activation of the prostaglandin system in response to sleep loss in healthy humans: potential mediator of increased spontaneous pain. Pain 145, 136-141.

Hapidou EG \& De Catanzaro D. (1988). Sensitivity to cold pressor pain in dysmenorrheic and non-dysmenorrheic women as a function of menstrual cycle phase. Pain $\mathbf{3 4}, \mathbf{2 7 7 - 2 8 3 .}$

Health NIo. (2005). National Institutes of Health State of the Science Conference statement on manifestations and management of chronic insomnia in adults, June 13-15, 2005. Sleep 28, 1049-1057. 
Hensel H, Andres KH \& von During M. (1974). Structure and function of cold receptors. Pflugers Arch 352, 1-10.

Herren RY. (1933). The effect of high and low female sex hormone concentration on the two-point threshold of pain and touch and upon tactile sensitivity.J Exp Psychol 16, 324.

Jensen R, Rasmussen BK, Pedersen B, Lous I \& Olesen J. (1992). Cephalic muscle tenderness and pressure pain threshold in a general population. Pain 48, 197-203.

Jones A, Zachariae R \& Arendt-Nielsen L. (2003). Dispositional anxiety and the experience of pain: gender-specific effects. Eur J Pain 7, 387-395.

Karacan I, Williams RL, Finley WW \& Hursch CJ. (1970). The effects of naps on nocturnal sleep: influence on the need for stage-1 REM and stage 4 sleep. Biol Psychiatry 2, 391-399.

Kayser V, Berkley KJ, Keita H, Gautron M \& Guilbaud G. (1996). Estrous and sex variations in vocalization thresholds to hindpaw and tail pressure stimulation in the rat. Brain research 742, 352-354.

Kenshalo DR \& Duclaux R. (1977). Response characteristics of cutaneous cold receptors in the monkey. J Neurophysiol 40, 319-332.

Kenshalo DR \& Nafe JP. (1962). A quantitative theory of feeling: 1960. Psychol Rev 69, 17-33.

Keogh E, Bond FW, Hanmer R \& Tilston J. (2005). Comparing acceptance- and control-based coping instructions on the cold-pressor pain experiences of healthy men and women. Eur J Pain 9, 591-598.

Keogh E, Hatton K \& Ellery D. (2000). Avoidance versus focused attention and the perception of pain: differential effects for men and women. Pain 85, 225-230.

Kim H, Neubert JK, Rowan JS, Brahim JS, Iadarola MJ \& Dionne RA. (2004). Comparison of experimental and acute clinical pain responses in humans as pain phenotypes. J Pain 5, 377-384.

Klatzkin RR, Mechlin B \& Girdler SS. (2010). Menstrual cycle phase does not influence gender differences in experimental pain sensitivity. Eur J Pain 14, 77-82.

Kleitman N. (1933). Studies on the physiology of sleep: VIII. Diurnal variation in performance. American Journal of Physiology--Legacy Content 104, 449-456. 
Klink ME, Quan SF, Kaltenborn WT \& Lebowitz MD. (1992). Risk factors associated with complaints of insomnia in a general adult population. Influence of previous complaints of insomnia. Arch Intern Med 152, 1634-1637.

Kowalczyk WJ, Evans SM, Bisaga AM, Sullivan MA \& Comer SD. (2006). Sex differences and hormonal influences on response to cold pressor pain in humans. J Pain 7, 151-160.

Krueger AB \& Stone AA. (2008). Assessment of pain: a community-based diary survey in the USA. Lancet 371, 1519-1525.

Kuczmierczyk AR \& Adams HE. (1986). Autonomic arousal and pain sensitivity in women with premenstrual syndrome at different phases of the menstrual cycle. J Psychosom Res 30, 421-428.

Kulpe O. (1905). Outlines of Psychology. 1893. Eng trans EB Titchener.

Kumazawa T \& Perl ER. (1977). Primate cutaneous sensory units with unmyelinated (C) afferent fibers. J Neurophysiol 40, 1325-1338.

Kundermann B, Spernal J, Huber MT, Krieg JC \& Lautenbacher S. (2004). Sleep deprivation affects thermal pain thresholds but not somatosensory thresholds in healthy volunteers. Psychosom Med 66, 932-937.

Lee KA. (1988). Circadian temperature rhythms in relation to menstrual cycle phase. J Biol Rhythms 3, 255-263.

Lentz MJ, Landis CA, Rothermel J \& Shaver JL. (1999). Effects of selective slow wave sleep disruption on musculoskeletal pain and fatigue in middle aged women. J Rheumatol 26, 1586-1592.

Light AR \& Perl ER. (1979). Spinal termination of functionally identified primary afferent neurons with slowly conducting myelinated fibers. J Comp Neurol 186, $133-150$.

Loomis AL, Harvey EN \& Hobart G. (1937). Cerebral states during sleep, as studied by human brain potentials. Journal of Experimental Psychology; Journal of Experimental Psychology 21, 127.

Lowery D, Fillingim RB \& Wright RA. (2003). Sex differences and incentive effects on perceptual and cardiovascular responses to cold pressor pain. Psychosom Med 65, 284-291. 
Lynn B \& Carpenter SE. (1982). Primary afferent units from the hairy skin of the rat hind limb. Brain research 238, 29-43.

Magendie F. (1822). Experiences sur les fonctions des racines des nerfs rachidiens. Journal de physiologie experimentale et pathologique 2, 276-279.

Manber R \& Bootzin RR. (1997). Sleep and the menstrual cycle. Health Psychol 16, 209-214.

Martinez-Gomez M, Cruz Y, Salas M, Hudson R \& Pacheco P. (1994). Assessing pain threshold in the rat: changes with estrus and time of day. Physiol Behav 55, 651-657.

McNatty KP, Hunter WM, MacNeilly AS \& Sawers RS. (1975). Changes in the concentration of pituitary and steroid hormones in the follicular fluid of human graafian follicles throughout the menstrual cycle. J Endocrinol 64, 555-571.

McNatty KP, Makris A, DeGrazia C, Osathanondh R \& Ryan KJ. (1979). The production of progesterone, androgens, and estrogens by granulosa cells, thecal tissue, and stromal tissue from human ovaries in vitro.J Clin Endocrinol Metab 49, 687-699.

Meijer JH \& Rietveld WJ. (1989). Neurophysiology of the suprachiasmatic circadian pacemaker in rodents. Physiol Rev 69, 671-707.

Melzack R \& Loeser JD. (1978). Phantom body pain in paraplegics: evidence for a central "pattern generating mechanism" for pain. Pain 4, 195-210.

Melzack R \& Wall PD. (1962). On the nature of cutaneous sensory mechanisms. Brain 85, 331-356.

Melzack R \& Wall PD. (1965). Pain mechanisms: a new theory. Science 150, 971-978.

Merskey H. (1991). The definition of pain. European psychiatry.

Moffitt PF, Kalucy EC, Kalucy RS, Baum FE \& Cooke RD. (1991). Sleep difficulties, pain and other correlates. J Intern Med 230, 245-249.

Moldofsky H \& Scarisbrick P. (1976). Induction of neurasthenic musculoskeletal pain syndrome by selective sleep stage deprivation. Psychosom Med 38, 3544. 
Moldofsky H, Scarisbrick P, England R \& Smythe H. (1975). Musculosketal symptoms and non-REM sleep disturbance in patients with "fibrositis syndrome" and healthy subjects. Psychosom Med 37, 341-351.

Molina N, Bedran-de-Castro MT \& Bedran-de-Castro JC. (1990). The role of opioids in the analgesic response of rats during the estrous cycle. Braz J Med Biol Res 23, 1157-1159.

Moore RY \& Eichler VB. (1972). Loss of a circadian adrenal corticosterone rhythm following suprachiasmatic lesions in the rat. Brain research 42, 201-206.

Morin CM, Gibson D \& Wade J. (1998). Self-reported sleep and mood disturbance in chronic pain patients. Clin J Pain 14, 311-314.

Muller J. (1841). Handbuch der Physiologie des Menschen. J. Holscher.

Murray EJ, Williams HL \& Lubin A. (1958). Body temperature and psychological ratings during sleep deprivation. J Exp Psychol 56, 271-273.

Myers CD, Robinson ME, Riley JL, 3rd \& Sheffield D. (2001). Sex, gender, and blood pressure: contributions to experimental pain report. Psychosom Med 63, 545550.

Neckelmann D, Mykletun A \& Dahl AA. (2007). Chronic insomnia as a risk factor for developing anxiety and depression. Sleep 30, 873-880.

Neri M \& Agazzani E. (1984). Aging and right-left asymmetry in experimental pain measurement. Pain 19, 43-48.

Nielsen CS, Stubhaug A, Price DD, Vassend O, Czajkowski N \& Harris JR. (2008). Individual differences in pain sensitivity: genetic and environmental contributions. Pain 136, 21-29.

Notermans SL \& Tophoff MM. (1967). Sex difference in pain tolerance and pain apperception. Psychiatr Neurol Neurochir 70, 23-29.

Older S, Battafarano D, Danning C, Ward J, Grady E, Derman S \& Russell I. (1998). The effects of delta wave sleep interruption on pain thresholds and fibromyalgia-like symptoms in healthy subjects; correlations with insulinlike growth factor I. J Rheumatol 25, 1180.

Onen SH, Alloui A, Gross A, Eschallier A \& Dubray C. (2001). The effects of total sleep deprivation, selective sleep interruption and sleep recovery on pain tolerance thresholds in healthy subjects. J Sleep Res 10, 35-42. 
Patkai P, Johannson G \& Post B. (1974). Mood, alertness and sympathetic-adrenal medullary activity during the menstrual cycle. Psychosom Med 36, 503-512.

Perl ER. (1968). Myelinated afferent fibres innervating the primate skin and their response to noxious stimuli. J Physiol 197, 593-615.

Perl ER. (2011). Pain mechanisms: a commentary on concepts and issues. Prog Neurobiol 94, 20-38.

Pfleeger M, Straneva PA, Fillingim RB, Maixner W \& Girdler SS. (1997). Menstrual cycle, blood pressure and ischemic pain sensitivity in women: a preliminary investigation. Int J Psychophysiol 27, 161-166.

Pilowsky I, Crettenden I \& Townley M. (1985). Sleep disturbance in pain clinic patients. Pain 23, 27-33.

Power JD, Perruccio AV \& Badley EM. (2005). Pain as a mediator of sleep problems in arthritis and other chronic conditions. Arthritis Care \& Research 53, 911919.

Pud D, Yarnitsky D, Sprecher E, Rogowski Z, Adler R \& Eisenberg E. (2006). Can personality traits and gender predict the response to morphine? An experimental cold pain study. Eur J Pain 10, 103-112.

Rainville P, Feine JS, Bushnell MC \& Duncan GH. (1992). A psychophysical comparison of sensory and affective responses to four modalities of experimental pain. Somatosens Mot Res 9, 265-277.

Ralph MR, Foster RG, Davis FC \& Menaker M. (1990). Transplanted suprachiasmatic nucleus determines circadian period. Science 247, 975-978.

Raymond I, Nielsen TA, Lavigne G, Manzini C \& Choiniere M. (2001). Quality of sleep and its daily relationship to pain intensity in hospitalized adult burn patients. Pain 92, 381-388.

Rechtschaffen A \& Kales A. (1968). A manual of standardized terminology, technique and scoring system for sleep stages of human sleep. Los Angeles Brain Information Service. Brain Information Institute, UCLA.

Reisbord LS \& Greenland S. (1985). Factors associated with self-reported back-pain prevalence: a population-based study. J Chronic Dis 38, 691-702.

Robin O, Vinard H, Vernet-Maury E \& Saumet JL. (1987). Influence of sex and anxiety on pain threshold and tolerance. Funct Neurol 2, 173-179. 
Robinson J \& Short R. (1977). Changes in breast sensitivity at puberty, during the menstrual cycle, and at parturition. British medical journal 1, 1188-1191.

Roehrs T, Hyde M, Blaisdell B, Greenwald M \& Roth T. (2006). Sleep loss and REM sleep loss are hyperalgesic. Sleep 29, 145-151.

Rollman GB \& Harris G. (1987). The detectability, discriminability, and perceived magnitude of painful electrical shock. Percept Psychophys 42, 257-268.

Roth T. (2007). Insomnia: definition, prevalence, etiology, and consequences. J Clin Sleep Med 3, S7-10.

Sanyal MK, Berger MJ, Thompson IE, Taymor ML \& Horne HW. (1974). Development of graafian follicles in adult human ovary. I. Correlation of estrogen and progesterone concentration in antral fluid with growth of follicles. Journal of Clinical Endocrinology \& Metabolism 38, 828-835.

Sarlani E, Farooq N \& Greenspan JD. (2003). Gender and laterality differences in thermosensation throughout the perceptible range. Pain 106, 9-18.

Schally AV, Arimura A, Kastin AJ, Matsuo H, Baba Y, Redding TW, Nair RM, Debeljuk L \& White WF. (1971). Gonadotropin-releasing hormone: one polypeptide regulates secretion of luteinizing and follicle-stimulating hormones. Science 173, 1036-1038.

Schiff JM. (1859). Lehrbuch der Physiologie des Menschen: I. Lehrbuch d. Muskel-u. Nervenphysiologie. M. Schauenburg.

Schmidt R, Schmelz M, Forster C, Ringkamp M, Torebjork E \& Handwerker H. (1995). Novel classes of responsive and unresponsive $C$ nociceptors in human skin. J Neurosci 15, 333-341.

Shechter A, Varin F \& Boivin DB. (2010). Circadian variation of sleep during the follicular and luteal phases of the menstrual cycle. Sleep 33, 647-656.

Sherman JJ, LeResche L, Mancl LA, Huggins K, Sage JC \& Dworkin SF. (2005). Cyclic effects on experimental pain response in women with temporomandibular disorders. J Orofac Pain 19, 133-143.

Sherrington C. (1947). The integrative action of the nervous system. CUP Archive.

Shibui K, Uchiyama M, Okawa M, Kudo Y, Kim K, Liu X, Kamei Y, Hayakawa T, Akamatsu T, Ohta K \& Ishibashi K. (2000). Diurnal fluctuation of sleep propensity and hormonal secretion across the menstrual cycle. Biol Psychiatry 48, 1062-1068. 
Silber MH, Ancoli-Israel S, Bonnet MH, Chokroverty S, Grigg-Damberger MM, Hirshkowitz M, Kapen S, Keenan SA, Kryger MH, Penzel T, Pressman MR \& Iber C. (2007). The visual scoring of sleep in adults. J Clin Sleep Med 3, 121131.

Sinclair DC. (1955). Cutaneous sensation and the doctrine of specific energy. Brain 78, 584-614.

Sivertsen B, Krokstad S, Overland S \& Mykletun A. (2009). The epidemiology of insomnia: associations with physical and mental health. The HUNT-2 study. $J$ Psychosom Res 67, 109-116.

Smith MT, Edwards RR, McCann UD \& Haythornthwaite JA. (2007). The effects of sleep deprivation on pain inhibition and spontaneous pain in women. Sleep 30, 494-505.

Smith MT, Perlis ML, Smith MS, Giles DE \& Carmody TP. (2000). Sleep quality and presleep arousal in chronic pain. J Behav Med 23, 1-13.

Smith YR, Stohler CS, Nichols TE, Bueller JA, Koeppe RA \& Zubieta JK. (2006). Pronociceptive and antinociceptive effects of estradiol through endogenous opioid neurotransmission in women. J Neurosci 26, 5777-5785.

Soares CN. (2005). Insomnia in women: an overlooked epidemic? Arch Womens Ment Health 8, 205-213.

Stening K, Eriksson O, Wahren L, Berg G, Hammar M \& Blomqvist A. (2007). Pain sensations to the cold pressor test in normally menstruating women: comparison with men and relation to menstrual phase and serum sex steroid levels. Am J Physiol Regul Integr Comp Physiol 293, R1711-1716.

Straneva PA, Maixner W, Light KC, Pedersen CA, Costello NL \& Girdler SS. (2002). Menstrual cycle, beta-endorphins, and pain sensitivity in premenstrual dysphoric disorder. Health Psychol 21, 358-367.

Toblin RL, Mack KA, Perveen G \& Paulozzi LJ. (2011). A population-based survey of chronic pain and its treatment with prescription drugs. Pain 152, 1249-1255.

Tousignant-Laflamme Y, Rainville P \& Marchand S. (2005). Establishing a link between heart rate and pain in healthy subjects: a gender effect. J Pain 6, 341-347. 
Ukponmwan OE, Rupreht J \& Dzoljic MR. (1984). REM sleep deprivation decreases the antinociceptive property of enkephalinase-inhibition, morphine and coldwater-swim. Gen Pharmacol 15, 255-258.

Unruh AM. (1996). Gender variations in clinical pain experience. Pain 65, 123-167.

Veith JL, Anderson J, Slade SA, Thompson P, Laugel GR \& Getzlaf S. (1984). Plasma beta-endorphin, pain thresholds and anxiety levels across the human menstrual cycle. Physiol Behav 32, 31-34.

Vgontzas AN, Liao D, Bixler EO, Chrousos GP \& Vela-Bueno A. (2009a). Insomnia with objective short sleep duration is associated with a high risk for hypertension. Sleep 32, 491-497.

Vgontzas AN, Liao D, Pejovic S, Calhoun S, Karataraki M \& Bixler EO. (2009b). Insomnia with objective short sleep duration is associated with type 2 diabetes: A population-based study. Diabetes Care 32, 1980-1985.

von Frey M. (1894). Beitrage zur physiologie des schmerzsinns. Akad Wiss Leipzig Math-Naturwiss Kl Ber 46, 185-196.

von Frey M. (1895). Beitrage zur Sinnesphysiologie der haut.

von Frey M. (1896). Untersuchungen uber die sinnesfunctionen der menschlichen haut: 1. Abhandlung: Druckempfindung und schmerz. S. Hirzel.

Webb WB \& Agnew HW, Jr. (1975). The effects on subsequent sleep of an acute restriction of sleep length. Psychophysiology 12, 367-370.

Weddell G. (1955). Somesthesis and the chemical senses. Annual review of psychology 6, 119-136.

Wittig RM, Zorick FJ, Blumer D, Heilbronn M \& Roth T. (1982). Disturbed sleep in patients complaining of chronic pain. J Nerv Ment Dis 170, 429-431. 


\section{Appendix A: Raw data for Study 1}

Table A.1. Anthropometric data

\begin{tabular}{|c|c|c|c|c|c|c|c|c|}
\hline \multirow[b]{2}{*}{$\begin{array}{l}\text { Subj- } \\
\text { ect }\end{array}$} & \multirow[b]{2}{*}{ Sex } & \multirow[b]{2}{*}{$\begin{array}{l}\text { Age } \\
\text { (yrs) }\end{array}$} & \multicolumn{3}{|c|}{ Normal Sleep } & \multicolumn{3}{|c|}{ 24-Hour Total Sleep Deprivation } \\
\hline & & & $\begin{array}{l}\text { Height } \\
\text { (cm) }\end{array}$ & $\begin{array}{c}\text { Weight } \\
\text { (kg) }\end{array}$ & $\begin{array}{c}\text { BMI } \\
(\mathrm{kg} / \mathrm{m} 2)\end{array}$ & $\begin{array}{l}\text { Height } \\
\text { (cm) }\end{array}$ & $\begin{array}{c}\text { Weight } \\
\text { (kg) }\end{array}$ & $\begin{array}{c}\text { BMI } \\
(\mathrm{kg} / \mathrm{m} 2)\end{array}$ \\
\hline 1 & $\mathrm{~F}$ & 22 & 168.0 & 73.5 & 26.04 & 167.0 & 73.2 & 26.25 \\
\hline 2 & M & 36 & 187.0 & 94.0 & 26.88 & 187.0 & 94.2 & 26.94 \\
\hline 3 & M & 20 & 183.0 & 100.5 & 30.01 & 182.0 & 100.0 & 30.19 \\
\hline 4 & M & 21 & 170.0 & 81.5 & 28.20 & 170.0 & 79.8 & 27.61 \\
\hline 5 & M & 26 & 169.0 & 59.5 & 20.83 & 170.0 & 60.0 & 20.76 \\
\hline 6 & M & 20 & 175.0 & 85.0 & 27.76 & 175.5 & 84.6 & 27.47 \\
\hline 7 & M & 18 & 180.0 & 91.0 & 28.09 & 180.0 & 91.5 & 28.24 \\
\hline 8 & M & 20 & 168.5 & 61.8 & 21.77 & 167.5 & 61.4 & 21.88 \\
\hline 9 & $\mathrm{M}$ & 18 & 173.0 & 63.0 & 21.05 & 173.0 & 62.0 & 20.72 \\
\hline 10 & M & 19 & 173.0 & 64.5 & 21.55 & 173.0 & 64.5 & 21.55 \\
\hline 11 & $\mathrm{M}$ & 20 & 189.0 & 95.5 & 26.73 & 189.0 & 96.0 & 26.87 \\
\hline 12 & $\mathrm{M}$ & 19 & 181.0 & 85.5 & 26.10 & 181.0 & 86.0 & 26.25 \\
\hline 13 & $\mathrm{~F}$ & 25 & 173.0 & 62.0 & 20.72 & 155.0 & 54.0 & 22.48 \\
\hline 14 & $\mathrm{~F}$ & 19 & 172.5 & 71.0 & 23.86 & 171.0 & 61.7 & 21.10 \\
\hline 15 & $\mathrm{M}$ & 19 & 173.0 & 70.0 & 23.39 & 173.0 & 70.5 & 23.56 \\
\hline 16 & $\mathrm{~F}$ & 18 & 160.0 & 50.5 & 19.73 & 159.5 & 50.5 & 19.85 \\
\hline 17 & $\mathrm{~F}$ & 18 & 160.0 & 63.0 & 24.61 & 160.0 & 62.5 & 24.41 \\
\hline 18 & $\mathrm{~F}$ & 18 & 162.0 & 63.5 & 24.20 & 160.0 & 63.5 & 24.80 \\
\hline 19 & $\mathrm{~F}$ & 28 & 171.0 & 97.0 & 33.17 & 170.5 & 96.0 & 33.02 \\
\hline 20 & $\mathrm{~F}$ & 23 & 169.5 & 63.5 & 22.10 & 168.5 & 67.5 & 23.77 \\
\hline 21 & $\mathrm{~F}$ & 24 & 160.0 & 53.0 & 20.70 & 158.0 & 53.5 & 21.43 \\
\hline 22 & M & 23 & 178.0 & 94.0 & 29.67 & 176.0 & 94.0 & 30.35 \\
\hline 23 & $\mathrm{M}$ & 24 & 167.5 & 65.0 & 23.17 & 167.0 & 64.5 & 23.13 \\
\hline 24 & $\mathrm{~F}$ & 26 & 159.5 & 57.0 & 22.41 & 159.5 & 58.0 & 22.80 \\
\hline 25 & $\mathrm{~F}$ & 27 & 176.0 & 60.5 & 19.53 & 175.0 & 61.0 & 19.92 \\
\hline 26 & $\mathrm{~F}$ & 19 & 165.5 & 53.5 & 19.53 & 163.5 & 53.5 & 20.01 \\
\hline 27 & $\mathrm{~F}$ & 19 & 167.5 & 72.5 & 25.84 & 167.5 & 74.5 & 26.55 \\
\hline
\end{tabular}

M, Male; F, Female; BMI, Body Mass Index 
Table A.2. Raw data for seated resting blood pressure ( $\mathrm{mmHg}$ ) and heart rate (beats/min).

\begin{tabular}{ccccc|cccc} 
& \multicolumn{5}{c}{ Normal Sleep } & & 24-Hour Total Sleep Deprivation \\
\cline { 2 - 9 } Subject & SAP & DAP & MAP & HR & SAP & DAP & MAP & HR \\
1 & 104.0 & 63.0 & 76.7 & 50.3 & 92.0 & 50.0 & 64.0 & 47.3 \\
2 & 104.0 & 59.3 & 74.2 & 53.3 & 126.7 & 67.7 & 87.4 & 47.3 \\
3 & 118.0 & 54.0 & 75.3 & 51.3 & 111.7 & 61.0 & 77.9 & 67.0 \\
4 & 118.7 & 70.0 & 86.2 & 73.3 & 106.0 & 66.0 & 79.3 & 55.7 \\
5 & 107.3 & 73.7 & 84.9 & 65.7 & 107.0 & 69.0 & 81.7 & 53.0 \\
6 & 116.3 & 86.3 & 96.3 & 85.7 & 108.0 & 75.0 & 86.0 & 67.3 \\
7 & 105.7 & 60.0 & 75.2 & 45.6 & 110.0 & 64.0 & 79.3 & 42.0 \\
8 & 105.7 & 56.7 & 73.0 & 55.0 & 117.0 & 71.7 & 86.8 & 55.0 \\
9 & 99.0 & 60.7 & 73.5 & 63.3 & 104.7 & 56.3 & 72.4 & 59.3 \\
10 & 96.3 & 63.7 & 74.6 & 81.0 & 105.0 & 74.0 & 84.3 & 73.0 \\
11 & 112.3 & 62.0 & 78.8 & 69.7 & 113.7 & 66.7 & 82.4 & 53.0 \\
12 & 121.3 & 67.7 & 85.6 & 52.0 & 115.0 & 63.7 & 80.8 & 55.0 \\
13 & 90.0 & 63.0 & 72.0 & 73.0 & 102.3 & 74.3 & 83.6 & 57.0 \\
14 & 102.0 & 76.3 & 84.9 & 87.7 & 105.0 & 74.3 & 84.5 & 61.7 \\
15 & 116.0 & 58.0 & 77.3 & 71.3 & 126.7 & 66.7 & 86.7 & 48.0 \\
16 & 90.0 & 59.3 & 69.5 & 81.3 & 103.3 & 70.3 & 81.3 & 59.0 \\
17 & 93.0 & 44.0 & 60.3 & 57.0 & 102.3 & 60.0 & 74.1 & 59.0 \\
18 & 101.3 & 62.0 & 75.1 & 71.3 & 111.3 & 63.3 & 79.3 & 63.0 \\
19 & 114.3 & 77.0 & 89.4 & 87.3 & 113.0 & 73.0 & 86.3 & 61.0 \\
20 & 108.7 & 77.7 & 88.0 & 59.3 & 115.7 & 81.0 & 92.6 & 47.0 \\
21 & 97.0 & 70.0 & 79.0 & 65.0 & 96.3 & 66.3 & 76.3 & 58.3 \\
22 & 107.3 & 60.0 & 75.8 & 52.3 & 120.7 & 71.7 & 88.0 & 64.3 \\
23 & 94.7 & 68.0 & 76.9 & 75.7 & 110.0 & 85.0 & 93.3 & 55.0 \\
24 & 88.7 & 57.3 & 67.8 & 77.0 & 89.7 & 57.3 & 68.1 & 65.3 \\
25 & 95.3 & 61.0 & 72.4 & 63.7 & 101.0 & 63.7 & 76.1 & 60.0 \\
26 & 96.0 & 63.0 & 74.0 & 61.3 & 99.7 & 74.0 & 82.6 & 66.7 \\
27 & 117.7 & 73.3 & 88.1 & 70.3 & 109.3 & 66.0 & 80.4 & 57.3
\end{tabular}

SAP, Systolic Arterial Pressure DAP, Diastolic Arterial Pressure MAP, Mean Arterial Pressure HR, Heart Rate 
Table A.3. Raw data for pain intensity during cold pressor test following normal sleep.

\begin{tabular}{|c|c|c|c|c|c|c|c|c|c|}
\hline \multirow[b]{2}{*}{ Subject } & \multicolumn{9}{|c|}{ Pain Intensity } \\
\hline & Base & $\begin{array}{l}15 \\
\text { sec }\end{array}$ & $\begin{array}{l}30 \\
\text { sec }\end{array}$ & $\begin{array}{l}45 \\
\text { sec }\end{array}$ & $\begin{array}{l}60 \\
\text { sec }\end{array}$ & $\begin{array}{l}75 \\
\text { sec }\end{array}$ & $\begin{array}{l}90 \\
\text { sec }\end{array}$ & $\begin{array}{l}105 \\
\text { sec }\end{array}$ & $\begin{array}{l}120 \\
\text { sec }\end{array}$ \\
\hline 1 & 6 & 8 & 9 & 10 & 11 & 12 & 12 & 13 & 13 \\
\hline 2 & 6 & 9 & 12 & 14 & 15 & 15 & 15 & 15 & 15 \\
\hline 3 & 6 & 7 & 11 & 13 & 13 & 14 & 14 & 12 & 11 \\
\hline 4 & 6 & 9 & 11 & 11 & 13 & 14 & 14 & 14 & 14 \\
\hline 5 & 6 & 11 & 13 & 14 & 13 & 12 & 12 & 11 & 12 \\
\hline 6 & 6 & 9 & 10 & 12 & 13 & 14 & 16 & 16 & 17 \\
\hline 7 & 6 & 12 & 13 & 15 & 15 & 14 & 14 & 14 & 14 \\
\hline 8 & 6 & 11 & 13 & 15 & 15 & 16 & 16 & 16 & 17 \\
\hline 9 & 6 & 7 & 9 & 11 & 12 & 14 & 15 & 15 & 14 \\
\hline 10 & 6 & 10 & 10 & 11 & 11 & 10 & 9 & 8 & 7 \\
\hline 11 & 6 & 11 & 13 & 14.5 & 15 & 16 & 16.5 & 16 & 15 \\
\hline 12 & 6 & 9 & 11 & 13 & 15 & 15 & 15 & 15 & 15 \\
\hline 13 & 6 & 10 & 13 & 15 & 16 & 16 & 15 & 14 & 14 \\
\hline 14 & 6 & 17 & 18 & 18 & 18 & 18 & 18 & 18 & 18 \\
\hline 15 & 6 & 8 & 8 & 9 & 9 & 10 & 11 & 11 & 12 \\
\hline 16 & 6 & 7 & 7 & 9 & 9 & 10 & 10 & 11 & 13 \\
\hline 17 & 6 & 6 & 6 & 6 & 6 & 6 & 6 & 6 & 6 \\
\hline 18 & 6 & 9 & 9 & 10 & 10 & 11 & 11 & 12 & 12 \\
\hline 19 & 6 & 10 & 13 & 14 & 14 & 14 & 14 & 15 & 15 \\
\hline 20 & 6 & 11 & 12 & 13 & 15 & 15 & 16 & 16 & 15 \\
\hline 21 & 6 & 11 & 12 & 14 & 14 & 16 & 17 & 20 & 20 \\
\hline 22 & 6 & 10 & 11 & 15 & 17 & 18 & 17 & 15 & 15 \\
\hline 23 & 6 & 15 & 17 & 17 & 18 & 17 & 18 & 18 & 18 \\
\hline 24 & 6 & 13 & 14 & 17 & 16 & 15 & 14 & 13 & 11 \\
\hline 25 & 6 & 9 & 10 & 11 & 13 & 13 & 13 & 13 & 13 \\
\hline 26 & 6 & 9 & 11 & 15 & 17 & 18 & 19 & 19 & 19 \\
\hline 27 & 6 & 9 & 10 & 11 & 13 & 13 & 12 & 11 & 11 \\
\hline
\end{tabular}

sec, seconds 
Table A.4. Raw data for pain intensity during cold pressor test following 24-hour total sleep deprivation.

\begin{tabular}{|c|c|c|c|c|c|c|c|c|c|}
\hline \multirow[b]{2}{*}{ Subject } & \multicolumn{9}{|c|}{ Pain Intensity } \\
\hline & Base & $\begin{array}{l}15 \\
\text { sec } \\
\end{array}$ & $\begin{array}{l}30 \\
\text { sec }\end{array}$ & $\begin{array}{l}45 \\
\text { sec } \\
\end{array}$ & $\begin{array}{l}60 \\
\mathrm{sec} \\
\end{array}$ & $\begin{array}{l}75 \\
\text { sec }\end{array}$ & $\begin{array}{l}90 \\
\text { sec }\end{array}$ & $\begin{array}{l}105 \\
\text { sec } \\
\end{array}$ & $\begin{array}{l}120 \\
\text { sec } \\
\end{array}$ \\
\hline 1 & 6 & 9 & 10 & 10 & 11 & 11 & 12 & 12 & 13 \\
\hline 2 & 6 & 13 & 15 & 15 & 15 & 17 & 18 & 18 & 18 \\
\hline 3 & 6 & 7 & 9 & 14 & 15 & 15 & 13 & 12 & 12 \\
\hline 4 & 6 & 8 & 10 & 15 & 15 & 15 & 16 & 16 & 16 \\
\hline 5 & 6 & 13 & 15 & 15 & 16 & 14 & 11 & 11 & 10 \\
\hline 6 & 6 & 9 & 12 & 15 & 15 & 17 & 17 & 18 & 18 \\
\hline 7 & 6 & 12 & 15 & 16 & 18 & 18 & 18 & 17 & 17 \\
\hline 8 & 6 & 9 & 10 & 13 & 13 & 14 & 15 & 17 & 17 \\
\hline 9 & 6 & 6 & 10 & 12 & 15 & 15 & 16 & 16 & 16 \\
\hline 10 & 6 & 15 & 17 & 17 & 17 & 18 & 17 & 15 & 13 \\
\hline 11 & 6 & 14 & 15 & 17 & 18 & 19 & 19 & 19 & 19 \\
\hline 12 & 6 & 9 & 11 & 12 & 12 & 13 & 14 & 14 & 14 \\
\hline 13 & 6 & 15 & 14 & 14 & 14 & 16 & 16 & 16 & 16 \\
\hline 14 & 6 & 17 & 17 & 17 & 17 & 17 & 17 & 17 & 17 \\
\hline 15 & 6 & 9 & 10 & 12 & 15 & 15 & 15 & 16 & 16 \\
\hline 16 & 6 & 7 & 9 & 11 & 13 & 15 & 17 & 17 & 17 \\
\hline 17 & 6 & 7 & 7.5 & 7.5 & 8 & 8 & 8 & 8 & 8 \\
\hline 18 & 6 & 9 & 9 & 10 & 10 & 10 & 10 & 10 & 11 \\
\hline 19 & 6 & 11 & 12 & 12 & 13 & 13 & 13 & 13 & 13 \\
\hline 20 & 6 & 15 & 16 & 17 & 17 & 18 & 18 & 18 & 18 \\
\hline 21 & 6 & 11 & 13 & 16 & 18 & 20 & 20 & 20 & 20 \\
\hline 22 & 6 & 15 & 16 & 18 & 19 & 16 & 14 & 14 & 16 \\
\hline 23 & 6 & 15 & 18 & 18 & 17 & 16 & 17 & 17 & 16 \\
\hline 24 & 6 & 15 & 15 & 17 & 15 & 15 & 15 & 13 & 13 \\
\hline 25 & 6 & 7 & 10 & 11 & 14 & 15 & 17 & 17 & 18 \\
\hline 26 & 6 & 11 & 13 & 15 & 16 & 18 & 18 & 18 & 18 \\
\hline 27 & 6 & 9 & 10 & 11 & 13 & 14 & 13 & 12 & 12 \\
\hline
\end{tabular}

sec, seconds 
Table A.5 Sleep hours for days preceding normal sleep and TSD testing sessions.

\begin{tabular}{|c|c|c|c|c|c|c|c|c|}
\hline \multirow[b]{2}{*}{ Subject } & \multicolumn{4}{|c|}{ Normal Sleep } & \multicolumn{4}{|c|}{ 24-Hour Total Sleep Deprivation } \\
\hline & Day 1 & Day 2 & Day 3 & Day 4 & Day 1 & Day 2 & Day 3 & Day 4 \\
\hline 1 & 7.00 & 8.00 & 8.00 & 7.75 & 7.50 & 7.00 & 7.25 & 0.00 \\
\hline 2 & 6.50 & 7.50 & 7.50 & 7.00 & 6.00 & 7.50 & 9.00 & 0.00 \\
\hline 3 & 7.00 & 8.00 & 8.00 & 6.00 & 5.00 & 6.00 & 7.50 & 0.00 \\
\hline 4 & 7.50 & 8.00 & 8.50 & 7.00 & 9.00 & 7.00 & 9.00 & 0.00 \\
\hline 5 & 8.50 & 5.00 & 8.75 & 7.25 & 9.75 & 5.50 & 10.25 & 0.00 \\
\hline 6 & 9.00 & 7.00 & 7.75 & 6.50 & 8.50 & 9.00 & 7.50 & 0.00 \\
\hline 7 & 8.00 & 8.00 & 6.50 & 6.25 & 4.50 & 7.75 & 7.50 & 0.00 \\
\hline 8 & 7.25 & 4.75 & 7.00 & 6.75 & 7.00 & 6.25 & 4.50 & 0.00 \\
\hline 9 & 6.25 & 6.75 & 6.00 & 6.75 & 7.00 & 3.75 & 6.00 & 0.00 \\
\hline 10 & 4.00 & 4.00 & 7.00 & 6.00 & 9.75 & 8.00 & 7.00 & 0.00 \\
\hline 11 & 9.75 & 5.50 & 7.75 & 5.50 & 8.00 & 9.00 & 7.00 & 0.00 \\
\hline 12 & 8.50 & 7.00 & 10.00 & 8.00 & 9.00 & 9.00 & 7.50 & 0.00 \\
\hline 13 & 8.00 & 8.00 & 8.00 & 6.50 & 6.00 & 7.00 & 7.00 & 0.00 \\
\hline 14 & 8.00 & 9.50 & 8.75 & 7.00 & 10.00 & 9.75 & 7.75 & 0.00 \\
\hline 15 & 7.50 & 10.00 & 7.75 & 6.50 & 9.00 & 10.50 & 7.75 & 0.00 \\
\hline 16 & 8.75 & 9.00 & 7.45 & 7.25 & 7.00 & 8.75 & 7.25 & 0.00 \\
\hline 17 & 7.00 & 8.00 & 8.00 & 7.00 & 10.50 & 7.50 & 6.50 & 0.00 \\
\hline 18 & 6.75 & 8.00 & 7.00 & 6.25 & 8.75 & 7.25 & 4.00 & 0.00 \\
\hline 19 & 9.50 & 8.50 & 6.50 & 7.00 & 7.00 & 8.50 & 9.00 & 0.00 \\
\hline 20 & 5.50 & 8.25 & 5.00 & 7.00 & 6.00 & 7.00 & 7.00 & 0.00 \\
\hline 21 & 7.00 & 7.75 & 7.00 & 7.00 & 7.00 & 5.00 & 7.50 & 0.00 \\
\hline 22 & 7.00 & 7.00 & 7.50 & 8.00 & 7.50 & 8.00 & 6.00 & 0.00 \\
\hline 23 & 6.00 & 8.50 & 7.50 & 7.50 & 6.75 & 9.00 & 8.75 & 0.00 \\
\hline 24 & 7.00 & 7.25 & 8.50 & 6.00 & 7.75 & 9.25 & 7.00 & 0.00 \\
\hline 25 & 9.50 & 8.00 & 7.50 & 7.50 & 7.75 & 8.00 & 8.00 & 0.00 \\
\hline 26 & 7.50 & 7.50 & 8.00 & 5.00 & 7.50 & 8.75 & 9.25 & 0.00 \\
\hline 27 & 7.00 & 4.50 & 6.50 & 4.50 & 5.25 & 5.00 & 7.00 & 0.00 \\
\hline
\end{tabular}

Bolded numbers denote subject self-reported sleep time. 
Table A.6 Sex hormone levels following Normal sleep and 24-hour total sleep deprivation.

\begin{tabular}{|c|c|c|c|c|}
\hline \multirow[b]{2}{*}{ Subject } & \multicolumn{2}{|c|}{ Normal Sleep } & \multicolumn{2}{|c|}{ 24-Hour Total Sleep Deprivation } \\
\hline & Estradiol pg/ml & Progesterone ng/ml & $\begin{array}{l}\text { Estradiol } \\
\mathrm{pg} / \mathrm{ml}\end{array}$ & Progesterone ng/ml \\
\hline 1 & 27 & 1.97 & 23 & 1.10 \\
\hline 2 & 16 & 1.57 & 24 & 1.99 \\
\hline 3 & 32 & 2.41 & 15 & 1.17 \\
\hline 4 & 14 & 3.17 & 16 & 3.10 \\
\hline 5 & 37 & 1.73 & 24 & 2.06 \\
\hline 6 & 29 & 3.65 & 21 & 2.46 \\
\hline 7 & 28 & 1.87 & 23 & 1.13 \\
\hline 8 & 19 & 2.50 & 16 & 1.65 \\
\hline 9 & 27 & 2.00 & 16 & 1.51 \\
\hline 10 & 39 & 2.32 & 24 & 1.88 \\
\hline 11 & 19 & 1.14 & 22 & 0.99 \\
\hline 12 & 22 & 2.23 & 20 & 1.28 \\
\hline 13 & 25 & 3.19 & 36 & 1.66 \\
\hline 14 & 30 & 2.77 & 25 & 1.83 \\
\hline 15 & 21 & 2.05 & 20 & 2.28 \\
\hline 16 & 41 & 1.38 & 37 & 0.42 \\
\hline 17 & 20 & 1.86 & 16 & 1.03 \\
\hline 18 & 27 & 2.12 & 23 & 1.36 \\
\hline 19 & 24 & 1.40 & 30 & 0.91 \\
\hline 20 & 20 & 2.12 & 21 & 0.79 \\
\hline 21 & 12 & 1.75 & 23 & 1.45 \\
\hline 22 & 23 & 1.83 & 19 & 1.93 \\
\hline 23 & 21 & 1.62 & 25 & 1.74 \\
\hline 24 & 52 & 1.29 & 42 & 1.46 \\
\hline 25 & 32 & 2.18 & 36 & 1.63 \\
\hline 26 & 130 & 3.25 & 47 & 2.31 \\
\hline 27 & - & - & - & - \\
\hline
\end{tabular}




\section{Appendix B: Summary of Statistics for Study 1}

\section{Mean data for Pain Intensity}

Table B.1 Mean data for $\Delta$ Pain Intensity during CPT

\begin{tabular}{l|c|c|c|c} 
Variable & Condition & N & Mean & Std. Error Mean \\
\hline$\Delta$ Pain Intensity & NS & 27 & 3.89 & 0.46 \\
$15 \mathrm{~s}$ & TSD & 27 & 5.00 & 0.63 \\
\hline$\Delta$ Pain Intensity & NS & 27 & 5.33 & 0.52 \\
30 s & TSD & 27 & 6.54 & 0.58 \\
\hline$\Delta$ Pain Intensity & NS & 27 & 6.87 & 0.54 \\
45 s & TSD & 27 & 7.98 & 0.54 \\
\hline$\Delta$ Pain Intensity & NS & 27 & 7.56 & 0.56 \\
60 s & TSD & 27 & 8.78 & 0.50 \\
\hline$\Delta$ Pain Intensity & NS & 27 & 7.93 & 0.54 \\
75 s & TSD & 27 & 9.26 & 0.52 \\
\hline$\Delta$ Pain Intensity & NS & 27 & 8.06 & 0.58 \\
$90 \mathrm{~s}$ & TSD & 27 & 9.33 & 0.55 \\
\hline$\Delta$ Pain Intensity & NS & 27 & 7.96 & 0.61 \\
105 s & TSD & 27 & 9.22 & 0.57 \\
\hline$\Delta$ Pain Intensity & NS & 27 & 7.93 & 0.62 \\
$120 \mathrm{~s}$ & TSD & 27 & 9.26 & 0.57 \\
\hline
\end{tabular}

Table B.2 $\Delta$ Mean \& Peak Pain Intensity during CPT

\begin{tabular}{l|c|c|c|c} 
Variable & Condition & N & Mean & Std. Error Mean \\
\hline$\Delta$ Mean Pain Intensity & NS & 27 & 6.95 & 0.50 \\
& TSD & 27 & 8.18 & 0.47 \\
\hline \multirow{2}{*}{ Peak Pain Intensity } & NS & 27 & 8.91 & 0.56 \\
& TSD & 27 & 10.22 & 0.51 \\
\hline
\end{tabular}

Table B.3 $\Delta$ Mean Pain Intensity during CPT by sex

\begin{tabular}{l|c|c|c|c|c} 
Variable & \multicolumn{1}{c}{ Condition } & Sex & \multicolumn{1}{c}{ N } & Mean & Std. Error Mean \\
\hline$\Delta$ Mean Pain & NS & M & 14 & 7.16 & 0.55 \\
Intensity & & F & 13 & 6.72 & 0.87 \\
\hline$\Delta$ Mean Pain & TSD & M & 14 & 8.70 & 0.48 \\
Intensity & & F & 13 & 7.62 & 0.82 \\
\hline
\end{tabular}




\section{Repeated Measures ANOVA}

Repeated measures ANOVA for baseline Weight (kg). Condition (NS vs. TSD) as within-subjects factor and sex (male vs. female) as between-subjects factor.

\begin{tabular}{|c|c|c|c|c|c|}
\hline \multicolumn{6}{|c|}{ Mauchley's Test of Sphericity } \\
\hline $\begin{array}{l}\text { Within Subjects } \\
\text { Effect }\end{array}$ & Mauchly's W & $\begin{array}{l}\text { Approx. Chi- } \\
\text { Square }\end{array}$ & df & Sig & $\begin{array}{l}\text { Huynh- } \\
\text { Feldt }\end{array}$ \\
\hline Condition & 1.000 & 0.000 & 0 & . & 1.000 \\
\hline \multicolumn{6}{|c|}{ Test of Within-Subjects Effects } \\
\hline Source & $\begin{array}{r}\text { Type III Sum of } \\
\text { Squares }\end{array}$ & df & Square & $\mathbf{F}$ & Sig. (2-tailed) \\
\hline Condition & 0.277 & 1.000 & 227 & 0.519 & 0.478 \\
\hline Condition $\times$ Sex & 0.997 & 1.000 & 997 & 1.867 & 0.184 \\
\hline \multicolumn{6}{|c|}{ Test of Between-Subjects Effects } \\
\hline Source & $\begin{array}{r}\text { Type III Sum of } \\
\text { Squares }\end{array}$ & df & Square & $\mathbf{F}$ & Sig. (2-tailed) \\
\hline Sex & 3317.238 & 1 & 7.238 & 8.921 & 0.006 \\
\hline
\end{tabular}

Repeated measures ANOVA for baseline SAP (mmHg). Condition (NS vs. TSD) as within-subjects factor and sex (male vs. female) as between-subjects factor.

\begin{tabular}{|c|c|c|c|c|c|}
\hline \multicolumn{6}{|c|}{ Mauchley's Test of Sphericity } \\
\hline $\begin{array}{l}\text { Within Subjects } \\
\text { Effect }\end{array}$ & Mauchly's W & $\begin{array}{l}\text { Approx. Chi- } \\
\text { Square }\end{array}$ & df & Sig & Huynh-Feldt \\
\hline Condition & 1.000 & 0.000 & 0 & & 1.000 \\
\hline \multicolumn{6}{|c|}{ Test of Within-Subjects Effects } \\
\hline Source & $\begin{array}{r}\text { Type III Sum of } \\
\text { Squares }\end{array}$ & df & Mean Square & $\mathbf{F}$ & Sig. (1-tailed) \\
\hline Condition & 178.446 & 1.000 & 178.446 & 9.725 & 0.003 \\
\hline Condition $\times$ Sex & 75.667 & 1.000 & 75.657 & 4.123 & 0.027 \\
\hline \multicolumn{6}{|c|}{ Test of Between-Subjects Effects } \\
\hline Source & $\begin{array}{r}\text { Type III Sum of } \\
\text { Squares }\end{array}$ & df & Mean Square & $\mathbf{F}$ & Sig. (1-tailed) \\
\hline Sex & 2780.500 & 1 & 2780.500 & 34.540 & 0.000 \\
\hline
\end{tabular}


Repeated measures ANOVA for baseline DAP (mmHg). Condition (NS vs. TSD) as within-subjects factor and sex (male vs. female) as between-subjects factor.

\begin{tabular}{|c|c|c|c|c|c|}
\hline \multicolumn{6}{|c|}{ Mauchley's Test of Sphericity } \\
\hline $\begin{array}{l}\text { Within Subjects } \\
\text { Effect }\end{array}$ & Mauchly's W & $\begin{array}{l}\text { Approx. Chi- } \\
\text { Square }\end{array}$ & df & Sig & $\begin{array}{l}\text { Huynh- } \\
\text { Feldt }\end{array}$ \\
\hline Condition & 1.000 & 0.000 & 0 & . & 1.000 \\
\hline \multicolumn{6}{|c|}{ Test of Within-Subjects Effects } \\
\hline Source & $\begin{array}{r}\text { Type III Sum o } \\
\text { Square }\end{array}$ & df & Mean Square & $\mathbf{F}$ & Sig. (1-tailed) \\
\hline Condition & 106.672 & 1.000 & 106.672 & 12.250 & 0.001 \\
\hline Condition $\times$ Sex & 1.639 & 1.000 & 1.639 & 0.188 & 0.334 \\
\hline \multicolumn{6}{|c|}{ Test of Between-Subjects Effects } \\
\hline Source & $\begin{array}{r}\text { Type III Sum o } \\
\text { Square }\end{array}$ & df & Mean Square & $\mathbf{F}$ & Sig. (1-tailed) \\
\hline Sex & 47.285 & 1 & 47.285 & 0.862 & 0.181 \\
\hline
\end{tabular}

Repeated measures ANOVA for baseline MAP (mmHg). Condition (NS vs. TSD) as within-subjects factor and sex (male vs. female) as between-subjects factor.

$\begin{array}{lcccccc}\text { Mauchley's Test of Sphericity } \\ \text { Within Subjects } & \text { Mauchly's W } & \begin{array}{c}\text { Approx. Chi- } \\ \text { Square }\end{array} & \text { df } & \text { Sig } & \begin{array}{c}\text { Huynh- } \\ \text { Effect }\end{array} \\ \text { Condition } & 1.000 & 0.000 & 0 & & . \\ & & & & 1.000\end{array}$

Test of Within-Subjects Effects

$\begin{array}{lccccc}\text { Source } & \begin{array}{c}\text { Type III Sum of } \\ \text { Squares }\end{array} & \text { df } & \text { Mean Square } & \text { F } & \text { Sig. (1-tailed) } \\ \text { Condition } & 127.841 & 1.000 & 127.841 & 16.313 & 0.000 \\ \text { Condition } \times \text { Sex } & 4.172 & 1.000 & 4.172 & 0.532 & 0.236\end{array}$

$\begin{array}{lcccccc}\text { Source } & \begin{array}{c}\text { Type III Sum of } \\ \text { Squares }\end{array} & \text { df } & \text { Mean Square } & \text { F } & \text { Sig. (1-tailed) } \\ \text { Sex } & 490.547 & 1 & 490.547 & 12.545 & 0.001\end{array}$


Repeated measures ANOVA for baseline Estradiol. Condition is within-subjects factor, sex is the between subjects-factor.

\begin{tabular}{|c|c|c|c|c|c|}
\hline \multicolumn{6}{|c|}{ Mauchley's Test of Sphericity } \\
\hline $\begin{array}{l}\text { Within Subjects } \\
\text { Effect }\end{array}$ & Mauchly's W & $\begin{array}{l}\text { Approx. Chi- } \\
\text { Square }\end{array}$ & df & Sig & $\begin{array}{l}\text { Huynh- } \\
\text { Feldt }\end{array}$ \\
\hline Condition & 1.000 & 0.000 & 0 & . & 1.000 \\
\hline \multicolumn{6}{|c|}{ Test of Within-Subjects Effects } \\
\hline Source & $\begin{array}{r}\text { Type III Sum of } \\
\text { Squares }\end{array}$ & df & Iean Square & $\mathbf{F}$ & Sig. (1-tailed) \\
\hline Condition & 403.718 & 1.000 & 403.718 & 2.561 & 0.062 \\
\hline Condition $\times$ & 17.411 & 1.000 & 17.411 & 0.110 & 0.372 \\
\hline \multicolumn{6}{|c|}{ Test of Between-Subjects Effects } \\
\hline Source & $\begin{array}{r}\text { Type III Sum of } \\
\text { Squares }\end{array}$ & df & Iean Square & $\mathbf{F}$ & Sig. (1-tailed) \\
\hline Sex & 1485.165 & 1 & 1485.165 & 4.054 & 0.028 \\
\hline
\end{tabular}

Repeated measures ANOVA for baseline Progesterone. Condition is within-subjects factor, sex is the between subjects-factor.

\begin{tabular}{|c|c|c|c|c|c|}
\hline \multicolumn{6}{|c|}{ Mauchley's Test of Sphericity } \\
\hline $\begin{array}{l}\text { Within Subjects } \\
\text { Effect }\end{array}$ & Mauchly's W & $\begin{array}{l}\text { Approx. Chi- } \\
\text { Square }\end{array}$ & df & Sig & $\begin{array}{l}\text { Huynh- } \\
\text { Feldt }\end{array}$ \\
\hline Condition & 1.000 & 0.000 & 0 & . & 1.000 \\
\hline \multicolumn{6}{|c|}{ Test of Within-Subjects Effects } \\
\hline Source & $\begin{array}{r}\text { Type III Sum of } \\
\text { Squares }\end{array}$ & df & Square & $\mathbf{F}$ & Sig. (1-tailed) \\
\hline Condition & 4.118 & 1.000 & 118 & 30.640 & 0.000 \\
\hline Condition $\times$ Sex & 0.587 & 1.000 & 587 & 4.364 & 0.024 \\
\hline \multicolumn{6}{|c|}{ Test of Between-Subjects Effects } \\
\hline Source & $\begin{array}{r}\text { Type III Sum of } \\
\text { Squares }\end{array}$ & df & Square & $\mathbf{F}$ & Sig. (1-tailed) \\
\hline Sex & 0.845 & 1 & 845 & 1.409 & 0.124 \\
\hline
\end{tabular}


Repeated measures ANOVA for $\triangle$ Pain Intensity during CPT. Condition and Time are within-subjects factors, sex is the between subjects-factor.

\begin{tabular}{|c|c|c|c|c|c|}
\hline \multirow{3}{*}{$\begin{array}{l}\text { Within Subjects } \\
\text { Effect } \\
\text { Condition }\end{array}$} & \multicolumn{3}{|c|}{ Mauchley's Test of Sphericity } & \multirow[b]{2}{*}{ Sig } & \multirow[b]{2}{*}{$\begin{array}{c}\text { Huynh- } \\
\text { Feldt }\end{array}$} \\
\hline & Mauchly's W & $\begin{array}{l}\text { Approx. Chi- } \\
\text { Square }\end{array}$ & df & & \\
\hline & 1.000 & 0.000 & 0 & . & 1.000 \\
\hline \multicolumn{6}{|c|}{ Test of Within-Subjects Effects } \\
\hline Source & $\begin{array}{r}\text { Type III Sum of } \\
\text { Squares }\end{array}$ & df & Mean Square & $\mathbf{F}$ & $\begin{array}{l}\text { Sig. (1- } \\
\text { tailed) }\end{array}$ \\
\hline Condition & 155.983 & 1.000 & 155.983 & 13.481 & 0.000 \\
\hline Condition $\times$ Sex & 5.778 & 1.000 & 5.778 & 0.499 & 0.244 \\
\hline Time & 3519.263 & 2.534 & 1388.564 & 93.908 & 0.000 \\
\hline Time $\times$ Sex & 25.205 & 2.534 & 9.945 & 0.673 & 0.274 \\
\hline $\begin{array}{l}\text { Condition } \times \\
\text { Time }\end{array}$ & 20.699 & 3.737 & 5.538 & 2.245 & 0.038 \\
\hline $\begin{array}{l}\text { Cond } \times \text { Time } \times \\
\text { Sex }\end{array}$ & 6.346 & 3.737 & 1.698 & 0.688 & 0.296 \\
\hline
\end{tabular}

Test of Between-Subjects Effects

$\begin{array}{lccccc}\text { Source } & \begin{array}{r}\text { Type III Sum of } \\ \text { Squares }\end{array} & \text { df } & \text { Mean Square } & \text { F } & \text { Sig. (1-tailed) } \\ \text { Sex } & 51.385 & 1 & 51.385 & 0.626 & 0.219\end{array}$

Repeated measures ANOVA for $\triangle$ Peak Pain Intensity during CPT. Condition is within-subjects factor, sex is the between subjects-factor.

\section{Within Subjects}

Effect

Condition

$\begin{array}{cc}\text { Mauchley's Test of Sphericity } \\ \text { Mauchly's W } & \begin{array}{c}\text { Approx. Chi- } \\ \text { Square }\end{array} \\ 1.000 & 0.000\end{array}$

df

0

Sig

Huynh-

Feldt

1.000

Test of Within-Subjects Effects

$\begin{array}{lccccc}\text { Source } & \begin{array}{c}\text { Type III Sum of } \\ \text { Squares }\end{array} & \text { df } & \text { Mean Square } & \text { F } & \text { Sig. (1-tailed) } \\ & 22.524 & 1.000 & 22.524 & 10.949 & 0.002 \\ \text { Condition } & 4.858 & 1.000 & 4.858 & 2.361 & 0.069\end{array}$

Test of Between-Subjects Effects

$\begin{array}{lccccc}\text { Source } & \begin{array}{c}\text { Type III Sum of } \\ \text { Squares }\end{array} & \text { df } & \text { Mean Square } & \text { F } & \text { Sig. (1-tailed) } \\ \text { Sex } & 13.892 & 1 & 13.892 & 1.044 & 0.159\end{array}$


Repeated measures ANOVA for $\triangle$ Average Pain Intensity during CPT. Condition is within-subjects factor, sex is the between subjects-factor.

Within Subjects
Effect
Condition

Source

Condition

Condition $\times$ Sex

Source

Sex

\begin{tabular}{cc}
\multicolumn{2}{c}{ Mauchley's Test of Sphericity } \\
Mauchly's W & $\begin{array}{c}\text { Approx. Chi- } \\
\text { Square }\end{array}$ \\
1.000 & 0.000
\end{tabular}

df

0
Sig Huynh- Feldt

1.000

Test of Within-Subjects Effects

$\begin{array}{ccccc}\begin{array}{c}\text { Type III Sum of } \\ \text { Squares }\end{array} & \text { df } & \text { Mean Square } & \text { F } & \text { Sig. (1-tailed) } \\ 19.995 & 1.000 & 19.995 & 12.131 & 0.001 \\ 1.362 & 1.000 & 1.362 & 0.826 & 0.186\end{array}$

Test of Between-Subjects Effects

$\begin{array}{ccccc}\begin{array}{c}\text { Type III Sum of } \\ \text { Squares }\end{array} & \text { df } & \text { Mean Square } & \text { F } & \text { Sig. (1-tailed) } \\ 7.768 & 1 & 7.768 & 0.702 & 0.205\end{array}$

\section{Post-hoc Paired T-Tests}

Men baseline SAP (mmHg)

Paired Samples Test

Paired Differences

\begin{tabular}{lccccccc}
\cline { 2 - 4 } Pairing & \multicolumn{3}{c}{$\mathbf{9 5 \% \text { Confidence Interval }}$} & & \multicolumn{1}{c}{ Sig. (1- } \\
tailed)
\end{tabular}

Women baseline SAP (mmHg)

Paired Samples Test

Paired Differences

$\mathbf{9 5 \%}$ Confidence Interval

Pairing

NS vs. TSD

Lower

Upper

$\mathbf{t}$

df

Sig. (1-

Mean

$-4.83$

2.29

$-0.776$

12

tailed)

0.227 
Men baseline Progesterone

Paired Samples Test

\begin{tabular}{|c|c|c|c|c|c|c|}
\hline \multirow[b]{3}{*}{ Pairing } & \multicolumn{3}{|c|}{ Paired Differences } & & & \multirow[b]{2}{*}{ Sig. (1- } \\
\hline & & $5 \%$ Cor & Interva & & & \\
\hline & Mean & Lower & Upper & $\mathbf{t}$ & df & tailed) \\
\hline NS vs. TSD & 0.351 & 0.022 & 0.680 & 2.308 & 13 & 0.019 \\
\hline
\end{tabular}

Women baseline Progesterone

Paired Samples Test

\begin{tabular}{|c|c|c|c|c|c|c|}
\hline \multirow[b]{3}{*}{ Pairing } & \multicolumn{3}{|c|}{ Paired Differences } & & & \multirow[b]{2}{*}{ Sig. (1- } \\
\hline & & $5 \%$ Con & Interval & & & \\
\hline & Mean & Lower & Upper & $\mathbf{t}$ & df & tailed) \\
\hline NS vs. TSD & 0.778 & 0.491 & 1.06 & 5.983 & 11 & 0.000 \\
\hline
\end{tabular}

$\Delta$ Pain Intensity during CPT

Paired Samples Test

Paired Differences

\begin{tabular}{|c|c|c|c|c|c|c|}
\hline \multirow[b]{2}{*}{ Pairing } & \multicolumn{4}{|c|}{ 95\% Confidence Interval } & & \multirow{2}{*}{$\begin{array}{l}\text { Sig. (1- } \\
\text { tailed) }\end{array}$} \\
\hline & Mean & Lower & Upper & $\mathbf{t}$ & df & \\
\hline NS $15 \mathrm{~s}$ vs. TSD $15 \mathrm{~s}$ & -1.11 & -1.92 & -0.03 & -2.82 & 26 & 0.005 \\
\hline NS 30s vs. TSD 30s & -1.20 & -2.03 & -0.04 & -3.01 & 26 & 0.003 \\
\hline NS $45 \mathrm{~s}$ vs. TSD $45 \mathrm{~s}$ & -1.11 & -1.87 & -0.35 & -3.02 & 26 & 0.003 \\
\hline NS 60s vs. TSD 60s & -1.22 & -2.16 & -0.28 & -2.67 & 26 & 0.007 \\
\hline NS 75s vs. TSD 75s & -1.33 & -2.32 & -0.35 & -2.78 & 26 & 0.005 \\
\hline NS 90s vs. TSD 90s & -1.28 & -2.31 & -0.25 & -2.55 & 26 & 0.009 \\
\hline $\begin{array}{l}\text { NS } 105 \text { s vs. TSD } \\
105 \mathrm{~s}\end{array}$ & -1.26 & -2.20 & -0.32 & -2.75 & 26 & 0.006 \\
\hline $\begin{array}{l}\text { NS 120s vs. TSD } \\
120 \mathrm{~s}\end{array}$ & -1.33 & -2.21 & -0.46 & -3.12 & 26 & 0.002 \\
\hline
\end{tabular}




\section{Appendix C: Raw data for Study 2}

Table C.1. Anthropometric data

\begin{tabular}{ccccc|ccc} 
& & \multicolumn{3}{c|}{ Early Follicular } & \multicolumn{3}{c}{ Mid-Luteal } \\
\cline { 2 - 7 } Subject & $\begin{array}{c}\text { Age } \\
(\mathbf{y r s})\end{array}$ & $\begin{array}{c}\text { Height } \\
(\mathbf{c m})\end{array}$ & $\begin{array}{c}\text { Weight } \\
\mathbf{( k g})\end{array}$ & $\begin{array}{c}\text { BMI } \\
(\mathbf{k g} / \mathbf{m})\end{array}$ & $\begin{array}{c}\text { Height } \\
(\mathbf{c m})\end{array}$ & $\begin{array}{c}\text { Weight } \\
(\mathbf{k g})\end{array}$ & $\begin{array}{c}\text { BMI } \\
(\mathbf{k g} / \mathbf{m} 2)\end{array}$ \\
\hline 1 & 19 & 164.5 & 65.5 & 24.21 & 163.5 & 65.5 & 24.50 \\
2 & 21 & 163.5 & 53.0 & 19.83 & 164.0 & 52.0 & 19.33 \\
3 & 19 & 177.5 & 70.0 & 22.22 & 179.0 & 70.0 & 21.85 \\
4 & 20 & 164.0 & 73.5 & 27.33 & 162.0 & 72.0 & 27.43 \\
5 & 21 & 167.0 & 79.0 & 28.33 & 166.5 & 76.5 & 27.60 \\
6 & 18 & 159.0 & 97.0 & 38.37 & 159.0 & 99.0 & 39.16 \\
7 & 30 & 168.0 & 95.0 & 33.66 & 170.0 & 94.5 & 32.70 \\
8 & 23 & 168.0 & 57.5 & 20.37 & 168.0 & 58.0 & 20.55 \\
9 & 19 & 165.5 & 56.0 & 20.45 & 166.0 & 57.0 & 20.69 \\
10 & 21 & 164.0 & 62.0 & 23.05 & 164.0 & 61.0 & 22.68
\end{tabular}

BMI, Body Mass Index

Table C.2. Raw data for seated resting blood pressure ( $\mathrm{mmHg}$ ) and heart rate (beats $/ \mathrm{min}$ ).

\begin{tabular}{ccccc|cccc} 
& \multicolumn{4}{c|}{ Early Follicular } & \multicolumn{4}{c}{ Mid-Luteal } \\
\cline { 2 - 8 } Subject & SAP & DAP & MAP & HR & SAP & DAP & MAP & HR \\
1 & 102.7 & 70.3 & 81.1 & 53.3 & 103.7 & 70.0 & 81.2 & 53.0 \\
2 & 97.3 & 70.7 & 79.6 & 53.3 & 97.3 & 66.7 & 76.9 & 53.7 \\
3 & 110.7 & 61.0 & 77.6 & 50.7 & 114.7 & 53.7 & 74.0 & 61.3 \\
4 & 83.0 & 79.3 & 80.5 & 68.0 & 94.3 & 54.3 & 67.6 & 70.7 \\
5 & 104.4 & 70.0 & 81.5 & 68.7 & 103.0 & 68.0 & 79.7 & 65.3 \\
6 & 103.0 & 63.3 & 76.5 & 70.0 & 98.3 & 68.7 & 78.6 & 65.3 \\
7 & 144.7 & 101.3 & 115.8 & 78.7 & 149.0 & 96.7 & 114.1 & 73.0 \\
8 & 96.7 & 55.3 & 69.1 & 56.7 & 102.3 & 53.0 & 69.4 & 62.3 \\
9 & 93.0 & 57.3 & 69.2 & 63.7 & 102.3 & 56.3 & 71.6 & 59.0 \\
10 & 119.0 & 65.7 & 83.5 & 56.0 & 101.0 & 58.0 & 72.3 & 55.7
\end{tabular}

SAP, Systolic Arterial Pressure

DAP, Diastolic Arterial Pressure

MAP, Mean Arterial Pressure

HR, Heart Rate 
Table C.3. Raw data for pain intensity during cold pressor test during Early Follicular Phase.

\begin{tabular}{|c|c|c|c|c|c|c|c|c|c|}
\hline \multirow[b]{2}{*}{ Subject } & \multicolumn{9}{|c|}{ Pain Intensity Early Follicular } \\
\hline & Base & $\begin{array}{l}15 \\
\text { sec }\end{array}$ & $\begin{array}{l}30 \\
\text { sec }\end{array}$ & $\begin{array}{l}45 \\
\text { sec }\end{array}$ & $\begin{array}{l}60 \\
\text { sec }\end{array}$ & $\begin{array}{l}75 \\
\text { sec }\end{array}$ & $\begin{array}{l}90 \\
\text { sec }\end{array}$ & $\begin{array}{l}105 \\
\text { sec }\end{array}$ & $\begin{array}{l}120 \\
\text { sec }\end{array}$ \\
\hline 1 & 6 & 15.0 & 15.0 & 16.0 & 17.0 & 17.0 & 15.0 & 15.0 & 14.0 \\
\hline 2 & 6 & 7.0 & 9.0 & 10.0 & 11.0 & 13.0 & 14.0 & 15.0 & 16.0 \\
\hline 3 & 6 & 9.0 & 13.0 & 17.0 & 17.0 & 18.0 & 15.0 & 15.0 & 17.0 \\
\hline 4 & 6 & 8.0 & 11.0 & 14.0 & 17.0 & 19.0 & 19.0 & 20.0 & 20.0 \\
\hline 5 & 6 & 16.0 & 18.0 & 19.0 & 19.0 & 19.0 & 17.0 & 16.0 & 15.0 \\
\hline 6 & 6 & 8.0 & 8.0 & 10.0 & 8.0 & 8.0 & 8.0 & 8.0 & 8.0 \\
\hline 7 & 6 & 18.0 & 20.0 & 20.0 & 20.0 & 20.0 & 20.0 & 20.0 & 20.0 \\
\hline 8 & 6 & 15.0 & 16.0 & 17.0 & 16.0 & 16.0 & 16.0 & 17.0 & 16.0 \\
\hline 9 & 6 & 9.0 & 11.0 & 12.0 & 12.0 & 14.0 & 13.0 & 13.0 & 13.0 \\
\hline 10 & 6 & 12.0 & 12.0 & 14.0 & 15.0 & 16.0 & 16.0 & 17.0 & 18.0 \\
\hline
\end{tabular}

Table C.4. Raw data for pain intensity during cold pressor test during Mid-Luteal Phase.

\begin{tabular}{|c|c|c|c|c|c|c|c|c|c|}
\hline \multirow[b]{2}{*}{ Subject } & \multicolumn{9}{|c|}{ Pain Intensity Mid-Luteal } \\
\hline & Base & $\begin{array}{l}15 \\
\text { sec }\end{array}$ & $\begin{array}{l}30 \\
\text { sec }\end{array}$ & $\begin{array}{l}45 \\
\text { sec }\end{array}$ & $\begin{array}{l}60 \\
\text { sec }\end{array}$ & $\begin{array}{l}75 \\
\text { sec }\end{array}$ & $\begin{array}{l}90 \\
\text { sec }\end{array}$ & $\begin{array}{l}105 \\
\text { sec }\end{array}$ & $\begin{array}{l}120 \\
\text { sec }\end{array}$ \\
\hline 1 & 6 & 17.0 & 18.0 & 18.0 & 17.0 & 16.0 & 16.0 & 15.0 & 15.0 \\
\hline 2 & 6 & 7.0 & 9.0 & 10.0 & 12.0 & 13.0 & 15.0 & 16.0 & 16.0 \\
\hline 3 & 6 & 7.0 & 8.0 & 18.0 & 18.0 & 16.0 & 16.0 & 14.0 & 12.0 \\
\hline 4 & 6 & 11.0 & 14.0 & 16.0 & 18.0 & 19.0 & 19.5 & 19.0 & 19.0 \\
\hline 5 & 6 & 16.0 & 15.0 & 15.0 & 17.0 & 15.0 & 14.0 & 12.0 & 10.0 \\
\hline 6 & 6 & 8.0 & 8.0 & 8.0 & 8.0 & 8.0 & 8.0 & 8.0 & 8.0 \\
\hline 7 & 6 & 11.0 & 18.0 & 20.0 & 20.0 & 20.0 & 18.0 & 18.0 & 18.0 \\
\hline 8 & 6 & 16.0 & 15.0 & 15.0 & 15.0 & 16.0 & 15.0 & 15.0 & 16.0 \\
\hline 9 & 6 & 9.0 & 10.0 & 10.0 & 12.0 & 13.0 & 13.0 & 12.0 & 13.0 \\
\hline 10 & 6 & 10.0 & 10.0 & 13.0 & 14.0 & 15.0 & 16.0 & 16.0 & 17.0 \\
\hline
\end{tabular}

sec, seconds 
Table C.5 Sleep hours for day preceding Early Follicular and Mid-Luteal testing sessions.

\begin{tabular}{ccccc|cccc} 
& \multicolumn{5}{c|}{ Early Follicular } & \multicolumn{5}{c}{ Mid-Luteal } \\
\cline { 2 - 9 } Subject & Day 1 & Day 2 & Day 3 & Day 4 & Day 1 & Day 2 & Day 3 & Day 4 \\
1 & 6.00 & 7.00 & 7.25 & 0.00 & 9.00 & 7.00 & 5.45 & 0.00 \\
2 & 7.00 & 5.00 & 6.00 & 0.00 & 6.25 & 8.75 & 6.25 & 0.00 \\
3 & 8.50 & 6.75 & $\mathbf{8 . 0 0}$ & 0.00 & 6.50 & 8.75 & 4.25 & 0.00 \\
4 & 7.75 & 8.25 & 7.25 & 0.00 & 7.00 & 8.00 & 8.25 & 0.00 \\
5 & $\mathbf{8 . 0 0}$ & 9.25 & 6.25 & 0.00 & 8.25 & 6.00 & 5.50 & 0.00 \\
6 & $\mathbf{6 . 0 0}$ & 8.50 & 5.00 & 0.00 & 9.50 & 6.50 & 5.75 & 0.00 \\
7 & 9.25 & 6.75 & 4.00 & 0.00 & 8.50 & 7.50 & 7.00 & 0.00 \\
8 & $\mathbf{1 0 . 5 0}$ & $\mathbf{9 . 0 0}$ & 8.25 & 0.00 & 6.50 & 7.00 & 7.00 & 0.00 \\
9 & 6.50 & 7.50 & 5.50 & 0.00 & 6.75 & 7.25 & 6.50 & 0.00 \\
10 & 7.75 & 8.75 & 8.50 & 0.00 & 7.25 & 8.00 & 9.50 & 0.00
\end{tabular}

Bold numbers denote subject reported sleep hours

Table C.6 Sex hormone levels during Early Follicular and Mid-Luteal Phases.

\begin{tabular}{ccc|cc} 
& \multicolumn{2}{c|}{ Early Follicular } & \multicolumn{2}{c}{ Mid-Luteal } \\
\cline { 2 - 5 } Subject & $\begin{array}{c}\text { Estradiol } \\
\mathbf{p g} / \mathbf{m l}\end{array}$ & Progesterone ng/ml & $\begin{array}{l}\text { Estradiol } \\
\text { pg/ml }\end{array}$ & $\begin{array}{c}\text { Progesterone } \mathbf{~ n g} / \mathbf{m l} \\
1\end{array}$ \\
25 & 3.14 & 28 & 3.02 \\
2 & 19 & 1.22 & 120 & 6.81 \\
3 & 15 & 1.06 & 31 & 1.74 \\
4 & 29 & 1.54 & 81 & 7.20 \\
5 & 26 & 1.22 & 44 & 1.11 \\
6 & 32 & 1.00 & 32 & 0.79 \\
7 & 22 & 0.78 & 89 & 8.06 \\
8 & 42 & 1.82 & 60 & 3.27 \\
9 & 33 & 1.30 & 87 & 10.20 \\
10 & 43 & 1.60 & 85 & 7.21
\end{tabular}




\section{Appendix D: Summary of Statistics for Study 2}

\section{Mean Data for Pain Intensity}

Table D.1 $\triangle$ Pain Intensity during CPT

\begin{tabular}{l|c|c|c|c} 
Variable & Condition & $\mathrm{N}$ & Mean & Std. Error Mean \\
\hline$\Delta$ Pain Intensity & $\mathrm{EF}$ & 10 & 5.7 & 1.27 \\
$15 \mathrm{~s}$ & $\mathrm{ML}$ & 10 & 5.2 & 1.21 \\
\hline$\Delta$ Pain Intensity & $\mathrm{EF}$ & 10 & 7.3 & 1.23 \\
$30 \mathrm{~s}$ & $\mathrm{ML}$ & 10 & 6.5 & 1.25 \\
\hline$\Delta$ Pain Intensity & $\mathrm{EF}$ & 10 & 8.9 & 1.11 \\
$45 \mathrm{~s}$ & $\mathrm{ML}$ & 10 & 8.3 & 1.26 \\
\hline$\Delta$ Pain Intensity & $\mathrm{EF}$ & 10 & 9.2 & 1.19 \\
$60 \mathrm{~s}$ & $\mathrm{ML}$ & 10 & 9.1 & 1.15 \\
\hline$\Delta$ Pain Intensity & $\mathrm{EF}$ & 10 & 10.0 & 1.14 \\
$75 \mathrm{~s}$ & $\mathrm{ML}$ & 10 & 9.1 & 1.06 \\
\hline$\Delta$ Pain Intensity & $\mathrm{EF}$ & 10 & 9.3 & 1.05 \\
90s & $\mathrm{ML}$ & 10 & 9.1 & 0.98 \\
\hline$\Delta$ Pain Intensity & $\mathrm{EF}$ & 10 & 9.6 & 1.10 \\
$105 \mathrm{~s}$ & $\mathrm{ML}$ & 10 & 8.5 & 1.01 \\
\hline$\Delta$ Pain Intensity & $\mathrm{EF}$ & 10 & 9.7 & 1.13 \\
$120 \mathrm{~s}$ & $\mathrm{ML}$ & 10 & 8.4 & 1.13 \\
\hline
\end{tabular}

Table D.2 $\Delta$ Mean \& Peak Pain Intensity during CPT

\begin{tabular}{l|c|c|c|c} 
Variable & Condition & N & Mean & Std. Error Mean \\
\hline \multirow{2}{*}{ Mean Pain Intensity } & EF & 10 & 8.72 & 1.02 \\
& ML & 10 & 8.03 & 0.93 \\
\hline \multirow{2}{*}{ Peak Pain Intensity } & EF & 10 & 10.9 & 0.96 \\
& ML & 10 & 10.3 & 1.11 \\
\hline
\end{tabular}




\section{Repeated Measures ANOVA}

Repeated measures ANOVA for $\triangle$ Pain Intensity during CPT. Condition and Time are within-subjects factors.

$\begin{array}{lccccc}\text { Within Subjects } & \text { Mauchly's W } & \begin{array}{c}\text { Mauchley's Test of Sphericity } \\ \text { Approx. Chi- } \\ \text { Square }\end{array} & \text { df } & \text { Sig } & \begin{array}{c}\text { Huynh- } \\ \text { Feldt }\end{array} \\ \begin{array}{l}\text { Effect } \\ \text { Condition }\end{array} & 1.000 & 0.000 & 0 & & 1.000\end{array}$

Test of Within-Subjects Effects

$\begin{array}{lccccc}\text { Source } & \begin{array}{c}\text { Type III Sum of } \\ \text { Squares }\end{array} & \text { df } & \text { Mean Square } & \text { F } & \text { Sig. (2-tailed) } \\ \text { Condition } & 17.112 & 1.000 & 17.112 & 2.884 & 0.124 \\ \text { Time } & 1530.428 & 3.485 & 439.195 & 23.142 & 0.000 \\ \text { Condition } \times \text { Time } & 8.050 & 5.213 & 1.544 & 0.972 & 0.447\end{array}$

Repeated measures ANOVA for $\triangle$ Peak Pain Intensity during CPT. Condition is within-subjects factor.

$\begin{array}{lccccc}\text { Within Subjects } & \text { Mauchly's W } & \begin{array}{c}\text { Mauchley's Test of Sphericity } \\ \text { Approx. Chi- } \\ \text { Square }\end{array} & \text { df } & \text { Sig } & \begin{array}{c}\text { Huynh- } \\ \text { Feldt }\end{array} \\ \begin{array}{l}\text { Effect } \\ \text { Condition }\end{array} & 1.000 & 0.000 & 0 & & .\end{array}$

Test of Within-Subjects Effects

$\begin{array}{lccccc}\text { Source } & \begin{array}{r}\text { Type III Sum of } \\ \text { Squares }\end{array} & \text { df } & \text { Mean Square } & \text { F } & \text { Sig. (2-tailed) } \\ \text { Condition } & 2.113 & 1.000 & 2.113 & 4.738 & 0.057\end{array}$

Repeated measures ANOVA for $\Delta$ Average Intensity during CPT. Condition is within-subjects factor.

$\begin{array}{lccccc}\begin{array}{l}\text { Within Subjects } \\ \text { Effect }\end{array} & \text { Mauchly's W } & \begin{array}{c}\text { Approx. Chi- } \\ \text { Square }\end{array} & \text { df } & \text { Sig } & \begin{array}{c}\text { Huynh- } \\ \text { Feldt }\end{array} \\ \text { Condition } & 1.000 & 0.000 & 0 & . & 1.000\end{array}$

Mauchley's Test of Sphericity

Test of Within-Subjects Effects

$\begin{array}{lccccc}\text { Source } & \begin{array}{c}\text { Type III Sum of } \\ \text { Squares }\end{array} & \text { df } & \text { Mean Square } & \text { F } & \text { Sig. (2-tailed) } \\ \text { Condition } & 2.380 & 1.000 & 2.380 & 2.890 & 0.123\end{array}$




\section{Paired T-Tests for Baseline Variables}

Paired t-test for Baseline Weight

Paired Samples Test

Paired Differences

\begin{tabular}{|c|c|c|c|c|c|c|}
\hline \multirow[b]{2}{*}{ Pairing } & \multicolumn{4}{|c|}{ 95\% Confidence Interval } & & \multirow{2}{*}{$\begin{array}{l}\text { Sig. (2- } \\
\text { tailed) }\end{array}$} \\
\hline & Mean & Lower & Upper & $\mathbf{t}$ & df & \\
\hline EF vs. ML & 0.3000 & -0.627 & 1.227 & 0.732 & 9 & \\
\hline
\end{tabular}

Paired t-test for Baseline BMI

Paired Samples Test

Paired Differences

\begin{tabular}{|c|c|c|c|c|c|c|}
\hline \multirow[b]{2}{*}{ Pairing } & \multicolumn{4}{|c|}{ 95\% Confidence Interval } & & \multirow{2}{*}{$\begin{array}{l}\text { Sig. (2- } \\
\text { tailed) }\end{array}$} \\
\hline & Mean & Lower & Upper & $\mathbf{t}$ & df & \\
\hline EF vs. ML & 0.133 & -0.252 & 0.518 & 0.781 & 9 & 0.455 \\
\hline
\end{tabular}

Paired t-test for Baseline SAP

Paired Samples Test

\begin{tabular}{lccccccc} 
& \multicolumn{3}{c}{ Paired Differences } & & & Sig. (2- \\
\cline { 2 - 4 } Pairing & \multicolumn{3}{c}{$\mathbf{9 5 \% \text { Confidence Interval }}$} & & & dailed) \\
EF vs. ML & -1.14 & -7.06 & 4.78 & -0.436 & 9 & 0.673
\end{tabular}

Paired t-test for Baseline DAP

\begin{tabular}{|c|c|c|c|c|c|c|}
\hline \multirow[b]{3}{*}{ Pairing } & \multicolumn{4}{|c|}{ Paired Samples Test } & & \multirow[b]{2}{*}{ Sig. (2- } \\
\hline & & $5 \% \mathrm{Cor}$ & Interv & & & \\
\hline & Mean & Lower & Upper & $\mathbf{t}$ & df & tailed) \\
\hline EF vs. ML & 4.88 & -0.843 & 10.61 & 1.929 & 9 & 0.086 \\
\hline
\end{tabular}

Paired t-test for Baseline MAP

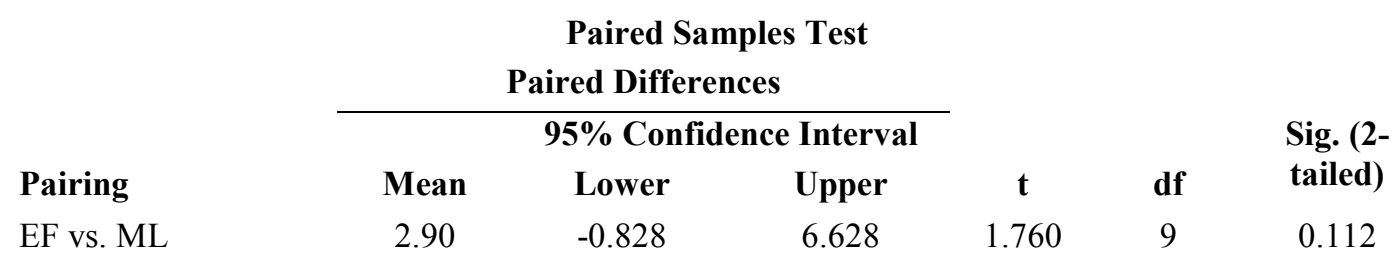


Paired t-test for Baseline HR

\begin{tabular}{|c|c|c|c|c|c|c|}
\hline \multirow[b]{3}{*}{ Pairing } & \multicolumn{3}{|c|}{$\begin{array}{l}\text { Paired Samples Test } \\
\text { Paired Differences }\end{array}$} & & & \multirow[b]{2}{*}{ Sig. (2- } \\
\hline & \multicolumn{4}{|c|}{$95 \%$ Confidence Interval } & & \\
\hline & Mean & Lower & Upper & $\mathbf{t}$ & df & tailed) \\
\hline EF vs. ML & -0.020 & -3.71 & 3.67 & -0.012 & 9 & 0.990 \\
\hline
\end{tabular}

Paired t-test for Baseline Estradiol

\begin{tabular}{|c|c|c|c|c|c|c|}
\hline \multirow[b]{3}{*}{ Pairing } & \multicolumn{3}{|c|}{$\begin{array}{l}\text { Paired Samples Test } \\
\text { Paired Differences }\end{array}$} & & \multirow[b]{3}{*}{ df } & \multirow{3}{*}{$\begin{array}{l}\text { Sig. (1- } \\
\text { tailed) }\end{array}$} \\
\hline & \multicolumn{4}{|c|}{ 95\% Confidence Interval } & & \\
\hline & Mean & Lower & Upper & $\mathbf{t}$ & & \\
\hline EF vs. ML & -37.10 & -60.00 & -14.20 & -3.67 & 9 & 0.003 \\
\hline
\end{tabular}

Paired t-test for Baseline Progesterone

\begin{tabular}{|c|c|c|c|c|c|c|}
\hline \multirow[b]{3}{*}{ Pairing } & \multicolumn{3}{|c|}{$\begin{array}{l}\text { Paired Samples Test } \\
\text { Paired Differences }\end{array}$} & & & \multirow{3}{*}{$\begin{array}{l}\text { Sig. (1- } \\
\text { tailed) }\end{array}$} \\
\hline & & $5 \%$ Con & Interva & & & \\
\hline & Mean & Lower & Upper & $\mathbf{t}$ & df & \\
\hline EF vs. ML & -3.47 & -5.96 & -0.984 & -3.16 & 9 & 0.006 \\
\hline
\end{tabular}


Appendix E: Modified Borg Scale Modified Borg Rating of Perceived Pain

\begin{tabular}{|c|c|}
\hline 6 & \\
\hline 7 & Very Low Pain \\
\hline 8 & \\
\hline 9 & Low Pain \\
\hline 10 & \\
\hline 11 & Fairly Painful \\
\hline 12 & \\
\hline 13 & Somewhat Painful \\
\hline 14 & \\
\hline 15 & Painful \\
\hline 16 & \\
\hline 17 & Very Painful \\
\hline 18 & \\
\hline 19 & Almost Unbearable \\
\hline 20 & \\
\hline
\end{tabular}

